\title{
Managers' cultural background and disclosure attributes
}

\section{Citation}

Brochet, Francois, Gregory S. Miller, Patricia Naranjo, and Gwen Yu. "Managers' Cultural Background and Disclosure Attributes." Harvard Business School Working Paper, No. 17-027, October 2016.

\section{Permanent link}

http://nrs.harvard.edu/urn-3:HUL.InstRepos:30903305

\section{Terms of Use}

This article was downloaded from Harvard University's DASH repository, and is made available under the terms and conditions applicable to Open Access Policy Articles, as set forth at http:// nrs.harvard.edu/urn-3:HUL.InstRepos:dash.current.terms-of-use\#OAP

\section{Share Your Story}

The Harvard community has made this article openly available.

Please share how this access benefits you. Submit a story.

Accessibility 


\section{Managers' Cultural Background and Disclosure Attributes}

Francois Brochet

Patricia Naranjo
Gregory S. Miller

Gwen $\mathrm{Yu}$

Working Paper 17-027 


\section{Managers' Cultural Background and Disclosure Attributes}

Francois Brochet

Boston University

Patricia Naranjo

Rice University
Gregory S. Miller

University of Michigan

Gwen $\mathrm{Yu}$

Harvard Business School

Working Paper 17-027 


\title{
Managers' cultural background and disclosure attributes
}

\author{
Francois Brochet \\ fbrochet@bu.edu \\ Gregory S. Miller \\ millerg@umich.edu \\ Patricia Naranjo \\ patricia.naranjo@ rice.edu \\ Gwen $\mathrm{Yu}^{*}$ \\ gyu@hbs.edu
}

\begin{abstract}
We examine how a manager's ethnic cultural background affects managers' communication with investors. Using a sample of earnings conference calls transcripts with 26,430 executives from 42 countries, we find that managers from ethnic groups that have a more individualistic culture (i) use a more optimistic tone, (ii) exhibit greater self-reference, and (iii) make fewer apologies in their disclosure narratives. Managers' ethnic culture has a lasting effect on their narratives - the effects persist even for executives who are later exposed to different ethnic cultures through work experience. The effect of ethnic heritage is observed in dialogues that reflect real time interactions (i.e., Q\&As) and less pronounced in the scripted, less spontaneous portion of the calls (i.e., management discussion). The capital market responds positively to optimistic tone yet does not distinguish between the optimism in tone of managers from different ethnic backgrounds. The findings suggest that managers' ethnic backgrounds have a significant effect on how they communicate with the capital markets and how the markets respond to the disclosure event.

Keywords: Disclosure tone, Cross-country culture, Individualism, Conference calls, Ethnic group

${ }^{*}$ Corresponding author: Harvard Business School, Morgan Hall 383, Boston, MA 02163, Tel: (617) 495-6547, Fax: (617) 496-7387, Email: gyu@hbs.edu.

We thank William Kerr for generously providing the ethnicity-name matches for the executives in our sample. We received helpful comments from Bill Mayew (discussant), Logan Steele (discussant), Anastasia Zakolyukina and workshop participants at the 2016 AAA annual meeting, the 2016 Berlin Accounting Workshop, Cornell, Georgetown University, IMO Conference at Harvard Business School, University of Chicago, University of Massachusetts Boston, University of Michigan Center of Law and Policy, Stanford University, Tilburg University, and Wharton. We are grateful for the research assistance of Peter Berard and Dylan Merrill. Yu acknowledges financial support from the Division of Research at Harvard Business School. Naranjo is grateful for financial support from Rice University. Miller is grateful for financial support from the Ernst \& Young chair at Ross School. All errors are our own.
\end{abstract}




\section{Introduction}

A growing literature demonstrates that culture has an impact on a wide range of economic activities (Guiso et al. 2006; Alesina and Giuliano 2015). This literature argues that shared values and preferences impact the way that people respond to economic incentives and the institutions that make up an economic system. Despite the apparent pervasive nature of culture, the accounting literature has provided little understanding of its impact on accounting information or capital market activities. In this study we begin to build that understanding by examining how the cultural background of executives, based on their ethnic heritage, affects the ways they communicate with the capital market.

We use insights developed from a long line of research in cultural psychology to examine how the communication style of individuals vary by ethnic groups. In particular, we focus on cultural characteristics associated with the extent to which an ethnic group is characterized to have an individualistic or collectivist culture. The individualism vs. collectivism cleavage is based on the extent to which individuals derive value from having an independent self-construct, as opposed to being strongly integrated into a cohesive group. This cultural dimension is considered the single most fruitful dimension in cross-cultural psychology (Heine 2008, 2010; Gorodnichenko and Roland 2012) and has been shown to correlate with individuals' preferences for their own achievement and recognition, in contrast to harmony and cooperation with others (Kitayama et al. 1997).

We hypothesize that individuals from cultures that are more individualistic disclose information in a more optimistic and self-referencing manner. The prediction is based on the psychology literature findings that in independent cultures (typically Western), there is greater demand to influence individuals through displays of optimism and self-confidence. Consequently, 
studies find that people from individualistic cultures seek to maximize the positive and minimize negative aspect of things more than people from collectivistic cultures (Sims et al. 2015). Also, self-attributions are more prevalent in cultures where independence is highly valued (Hallahan et al. 1997; Heine et al. 1999).

Conference calls present a unique disclosure event as they include both a scripted, prerehearsed portion (management discussion) at the beginning of most calls followed by the more extemporaneous Q\&A section at the end. Prior research argues that conference calls provide relevant information to investors because much of their information is disclosed interactively, which allows for more extemporaneous disclosures that address the specific concerns of those participating in the calls (Matsumoto et al. 2011; Lee 2016). For this reason, we focus on the Q\&A portion of the calls for our main empirical test. Further, we expect that these unscripted responses are more likely to be influenced by managers' informal communication style than would a scripted speech. Consistent with that, prior studies show that cultural attributes are more likely to be reflected when the disclosure is more extemporaneous (Gluszek and Dovidio 2010). Thus, we expect ethnic cultural background to have more of an impact in the Q\&A section of the conference call.

We apply content analysis to executives' disclosure narratives during earnings conference calls to capture the executives' level of optimism and self-confidence. In particular, we examine three disclosure attributes measured at the individual manager-level: tone, self-reference, and apologies. Disclosure tone captures the level of optimism (Loughran and McDonald 2011). Selfreference is the extent to which individuals implicates the self during the information releases, measured as the prevalence of the use of singular first personal pronouns during the calls. Both self-reference and apologies are more closely related to self-confidence (Chatterjee and Hambrick 
2007; Libby and Rennekamp 2012; Okimoto et al. 2013). We use these measures as empirical constructs of our predictions of optimism and self-confidence. Specifically, we expect that managers from a more individualistic ethnic background speak in ways that are more optimistic (i.e., more positive tone) and self-confident (i.e., greater self-reference and fewer apologies). ${ }^{1}$

We identify the ethnic group of executives based on their surnames in the conference call transcripts. We match each surname to an ethnic group using the ethnicity-name matching technique developed by Kerr (2008). The matching algorithm uses the name databases of two marketing companies, Melissa Data Corporation and List Services Direct, Inc., which developed them for use in direct-mail advertisements. The technique classifies each name into nine distinct ethnic groups: Anglo-Saxon, Chinese, European, Hispanic, Indian, Japanese, Korean, Russian/Slavic, and Vietnamese. ${ }^{2}$ After identifying the ethnic background of each executive, we assign an individualism score, which varies by each ethnic group based on data from Hofstede (2001). We use that measure to examine the impact of culture on the conference call disclosure attributes.

We find that managers from individualistic cultures are likely to use a more positive tone, use greater self-reference, and make fewer apologies. ${ }^{3}$ The findings hold after controlling for contemporaneous fundamentals (including the earnings news), other country-level factors that

\footnotetext{
${ }^{1}$ Nonetheless, in an increasingly global economy, capital and labor market forces may dilute the effect of top-level executives' cultural roots on their communication with an international audience. This, among other reasons, forms the basis for our null hypothesis.

${ }^{2}$ The matching procedure utilizes all of the name assignments in the database and assigns a probability distribution of each name, giving first priority to surnames. While other data vendors provide similar services, the advantage of the database provided by these companies is in their identification of Asian ethnicities, especially Chinese, Indian, Japanese, Korean, Russian/Slavic, and Vietnamese names (Kerr 2008). See Appendix A and Kerr (2008) for more details on the matching process.

${ }^{3}$ We use the Q\&A portion of the calls to focus on real-time communication. The Q\&A portion of the calls is less likely to be scripted than the management discussions, and therefore is more likely to reflect the preferences of the speaking manager rather than the firm (e.g., legal counsel or the IR department). In subsequent analysis, we show how cultural effects differ in the management discussion section which tend to be less interactive and more scripted.
} 
may affect information environments and disclosure quality in different countries, and other manager characteristics such as age and gender. Our findings also continue to hold when we limit our sample to executives from companies based in a single country (the US). Hence, our results are not driven by differences in country-level institutions.

Next we turn to the persistence of managers' inherited cultural influence on their disclosure. We find that the cultural traits that executives inherit from their ethnic groups are long lived. We examine executives who are later exposed to different cultures, through cross cultural work experience or education. While we find that these executives express themselves in a way that is less reflective of their inherited individualism than their non-exposed peers, the impact of the inherited culture still remains at a significant level. Also, the effects persist regardless of whether the firm is releasing positive or negative news, suggesting that disclosure incentives do not mitigate the effect of culture. ${ }^{4}$

While prior research generally measures conference call attributes such as tone at the firm level, we show that individual manager's cultural backgrounds impact their communication. Having shown this "first moment" impact, we examine the impact that diversity of cultural backgrounds creates in the variation in the overall tone of the firm. That is, we examine whether the standard deviation of tone across individuals is greater when there is a greater ethnic diversity on the management team. We find evidence consistent with diversity in cultural increasing variance in communication within an individual conference call. This suggests that firms with a more diverse management group may send a less consistent message during the call.

The empirical tests thus far focus on the Q\&A section of the calls. In additional tests, we use the management discussion (MD) section of the call and examine whether the cultural effects

\footnotetext{
${ }^{4}$ For example, it is possible that managers may have more incentive to self-reference when they are communicating good news than bad news (Kimbrough and Wang 2014).
} 
of managers' disclosure vary by whether the disclosure is extemporaneous. For our research question, this distinction is important as it allows us to examine the scripted, formal preplanned introductory remarks in the MDs and compare them to extemporaneous Q\&A. The MD section of the calls are often referred to as "prepared remarks" and often created by a team which includes the manager and communication specialist (Lee 2016). Further, they are generally read off a script or even prerecorded. The preparers may unintentionally weaken the impact of culture in this groupcreated disclosure simply because members of the group likely come from different backgrounds. There may also be a more purposeful mitigation of any ethnically driven communication differences. Consistent with cultural attributes being reflected in more interactive extemporaneous disclosures, we find that the Q\&A section more strongly reflects the ethnic origins of the speakers than the MD section. In fact, in the MD section of the call, we find evidence of firms/managers overcompensating for their cultural attributes. This finding suggests that cultural attributes are more likely to surface in real-time interactive disclosures and firms may take measures to overcome such cultural preferences.

Our results are robust to a wide range of specifications. Our main specification is a manager-level regression of disclosure attributes on managers' individualism based on their ethnic backgrounds. The regressions control for executive, conference call, firm, and country characteristics. As alternatives, we include firm fixed effects and use only within firm variation in managers' ethnicity, primarily driven by ethnic diversity in the management team. ${ }^{5}$ Also, we restrict the sample to conference calls held by U.S. firms to minimize the possibility that our results could be driven by unobserved country characteristics. We find robust results.

\footnotetext{
${ }^{5}$ We also document significant effects using a changes analysis, with the exception of self-reference. By using the changes in the ethnic mix of the management team from one call to another we are able to better control for unobserved firm-level factors that drive the observed association.
} 
The primary goal of our paper is to examine the impact of cultural background on information provided to the markets. For completeness purposes, we examine the capital market's response to the difference in disclosure tones stemming from the executives' cultural backgrounds. We first examine tone without conditioning on cultural backgrounds. We confirm that the association found in prior literature also exists in our sample. That is, optimistic tone is associated with positive cumulative abnormal intra-day returns during the conference calls. However, we find no evidence that the market differentiates the disclosure tone of managers from different ethnic backgrounds. That is, positive tone leads to similar market returns regardless of the management team's ethnic makeup despite the fact that we have shown the tone is influenced by that ethnic makeup. Both of these findings suggest that capital market participants do not adjust for managerial cultural background when processing the implications of tone for firm value

Our paper contributes to the literature by examining the importance of individual managers' ethnic cultural backgrounds on the disclosure provided by firms. Despite theoretical arguments for the important role that culture plays in shaping individual behavior (Robalino and Robson 2013; Karolyi 2015), empirical evidence on how this shaping manifests in the context of corporate reporting is largely missing. Our study shows that cultural heritage has an economically meaningful impact on corporate disclosure, thus providing important evidence on the existence of the cultural transmission of managerial behavior through ethnic groups. Further, by showing that the impact is greater in extemporaneous disclosures, our study highlights the need to consider the impact on different components of disclosure differently. For example, we may not see a large impact on formal written communication, such as earnings announcements, but we would expect a large impact on informal personal interactions such as the Q\&A studied here that are increasingly being shown to be important. 
Second, our research also contributes to the literature on how CEO characteristics affect firm policies. Bertrand and Schoar (2003) were the first to show the existence of CEO fixed effects in corporate outcomes, and Davis et al. (2014) subsequently document a manager-specific component to disclosure tone and its value-relevance. Other papers have looked at specific traits of individuals (Malmendier et al. 2011; Roussanov and Savor 2012). We add to this literature by showing that managers' cultural backgrounds, by shaping their values and preferences in the early stages of their lives, affect corporate disclosure policy. In contrast to prior studies that show that work experience shapes the preference of managers (e.g., Dittmar and Duchin, 2015), we show that the role of inherited cultural background is long lasting and persists even when individuals are later exposed to different cultures.

Finally, we contribute to the growing literature on corporate culture (Guiso et al 2015; Graham et al. 2015). Hofstede et al. (1990) argue that ethnic cultures form one's values through early socialization, while corporate culture acquired through work experience involves the subsequent acquisition of organizational practices (Van den Steen 2010). To the extent that individuals' values inherited through their cultural background are difficult to alter, the findings have implications for the effects of corporate culture that are acquired later on in one's career.

\section{Hypothesis development}

2.1 Inherited culture and disclosure attributes

A recent literature in accounting and finance examines the linguistic properties of corporate financial disclosures. One of the most studied dimensions is disclosure tone, i.e., the relative use of words that are considered positive versus negative. While the positive association between disclosure tone and contemporaneous measures of economic performance is an empirical regularity (Feldman et al. 2010; Price et al. 2012; Huang et al. 2014), little is known about the 
broader determinants of tone. Davis et al. (2014) offer evidence that an executive's own preferences have a significant effect on disclosure tone. They document a significant managerspecific component to tone in U.S. firms' earnings conference calls and further show that a manager's tone is more positive for those who are involved in charitable organizations, and lower for former investment bankers and those who were born during a recession. While these results offer clues about which speakers' characteristics can shape disclosure tone, the question remains open as to where these managerial characteristics come from. Also, it remains unknown whether the styles of the individuals represent characteristics that a person inherits or whether they are situational.

In this paper, we examine how the cultural backgrounds of individual managers - based on their ethnic heritage — affect their disclosure narrative. The cultural psychology literature has long shown that the individualism vs. collectivism dimension has a strong effect on how individuals communicate and interact with others (Markus and Kitayama 1991). Individualism refers to the degree to which people focus on their internal attributes, such as their own abilities, to differentiate themselves from others (Hofstede 2001). Studies find that cultures with strong individualism tend to have an independent rather than an interdependent self-construct (Chui et al. 2010). In individualistic cultures, individuals tend to view themselves as "an autonomous, independent person” (Markus and Kitayama (1991, p. 226)), while in collectivistic cultures, individuals view themselves "not as separate from the social context but as more connected and less differentiated from others" (Markus and Kitayama (1991, p. 227)).

Prior literature has found individualism to be related to several behavioral patterns. In the finance literature, Chui et al. (2010) argue that individualism is related to cross-country differences in overconfidence. The authors show that in countries with high individualism, there are greater 
returns to momentum trading strategies-where stocks that realize the best (worst) returns continue to perform well (poorly) in the future. The psychology literature also links individualistic cultures and self-attribution, defined as the tendency of people to "enhance or protect their selfesteem by taking credit for success and denying responsibility for failure" (Zuckerman 1979, p. 245). Kagitcibasi (1997) argues that that the tendency to promote self-esteem in individualistic cultures results in pervasive self-attribution as well as overconfidence. Even if positivity can be observed across cultures, Hallahan et al. (1997) show that in Western cultures where individualism and uniqueness are highly valued, self-referencing is more prevalent. In contrast, self-referencing is less prevalent in Eastern cultures, because standing out or stressing one's superiority sets one apart from their peers, which is viewed negatively in collectivist cultures (Kobayashi and Brown 2003).

Apologies can also be symptomatic of individuals' self-esteem (Okimoto et al. 2013). Across cultures, several studies find that Japanese individuals apologize more often than their American counterparts (Takagi 1996; Sugimoto 1997). Maddux et al. (2011) argue that this is due to individualistic (such as the U.S.) and collectivist (such as Japan) cultures using apologies for different reasons: Individualistic cultures consider apologies as a self-denigrating act and mechanism to assign blame, whereas collectivist cultures use it as a general expression of remorse. In collectivist cultures, apologies reflect one's concern of being imposing on others; they serve to minimize the individual, even in situation where responsibility is clearly absent (Heine et al. 1999).

Prior studies also find a positive link between individualism and optimism. Triandis (1995) argues that individualism is positively associated with levels of self-esteem and feelings of wellbeing. While individuals from Western cultures exhibit optimism bias (Taylor and Brown 1988), those from Eastern cultures exhibit greater self-criticism (Markus and Kitayama 1991; Kitayama 
et al. 1997). Similarly, Heine et al. (1999) find that people in individualistic cultures, such as the United States, tend to believe that their abilities are above average. In contrast, people in collectivist cultures are concerned with behaving appropriately and adapting to different social situations. They tend to have high self-monitoring and adjust their behavior to what is expected in their social environment (Biais et al. 2005).

Hence, insofar as an optimistic predisposition translates into an individual's choice of words, it follows that individuals from more individualistic cultures (and thus more optimistic ones) are more likely to express themselves in a positive, self-referencing, non-apologetic tone. ${ }^{6}$ We formulate our first hypothesis directionally:

H1: Managers with an ethnic background from a more individualistic culture exhibit a more positive, self-referencing, and non-apologetic tone, controlling for the underlying earnings news.

We posit that ethnic background plays a role in the degree to which an individual inherits a more individualistic or collectivist cultural background, primarily through their upbringing. Furthermore, we argue that inherited cultural heritage will have a lasting effect on the individual. In other words, cultural heritage will have a persistence effect on the individual, which withstands the situational forces and other experiences the individuals are exposed to after birth. We test this conjecture by examining the strength of the effect of ethnic heritage for a subsample of managers that are later exposed to other cultures through work experience. For such executives, it is possible that they are 'made' to speak in a way that is more consistent with a different ethnic group.

\footnotetext{
${ }^{6}$ It is worthy to note that many of the managers included in our study are non-native speakers of English. Thus, underlying our prediction is the assumption that cultural differences, as captured by tone and other similar linguistic patterns, are reflected in the disclosures, even if the speakers do not speak in their mother tongue (Brochet et al. 2016). This assumption can be violated if cultural differences are lost in translation. For example, English learners can be influenced by instructors and/or materials that reflect Anglo-Saxon individualism/optimism. Alternatively, a culture's tendency towards greater individualism/optimism may only be captured by the domestic language: For example, languages in individualistic cultures are less likely to allow for pronoun drop than those in collectivist cultures (Kashima and Kashima 1998).
} 
Furthermore, top executives of large international corporations are likely amenable to making such changes. For example, if an American-born CEO works at a Japanese company, the influence of his/her colleagues and work environment might induce him/her to speak in ways that are more consistent with the Japanese culture. Hence, executives later exposed to cultures that are different from their ethnic inheritance may be affected by the behavioral traits of the new culture.

If individuals' values inherited through their cultural background are difficult to alter, inherited cultures will have a lasting effect on individuals' disclosure. However, if the acquired culture can be learned through continuous exposure to the point of dominating the inherited culture, the effect of inherited culture may be muted. In our second hypothesis, we test the relative strength of inherited ethnic cultures for those who have vs. have not been exposed to a different ethnic culture later on in their career.

H2: For managers with greater exposure to ethnic cultures that are different from their own, the effect of the inherited ethnic background on disclosure attributes will be weaker.

Next, we examine whether the effect of ethnic backgrounds on disclosure outcomes varies by disclosure venue. While the effect of ethnic culture may be long lasting for an individual, there could be forces that can "undo" the cultural component of their disclosure tone. Because conference calls are important events that provide relevant information to investors, there are other institutional forces that may affect how the managers speak. Therefore, if people involved with disclosures (legal departments, investor relations group) are fully aware of cultural differences, it is likely that they adjust for those differences to conform to some global norm in order to change outsiders' perceptions. We exploit the dual nature of earnings conference calls and test for the different effect of culture for more vs. less extemporaneous disclosure venues. 
We consider the Q\&A section, which is highly interactive, to be more extemporaneous and the MD section to be more scripted and less extemporaneous. We predict that individual managers' cultural attributes are reflected more in the Q\&A section than in the MD section, where other firm-level efforts are more likely to shape the disclosure tone of managers. Hence, managers may show no evidence of disclosure style consistent with their ethnic backgrounds, and may even show signs of overcompensation for their cultural attributes.

H3: The effect of ethnic background on disclosure attributes will be stronger when the communication is more extemporaneous (i.e., Q\&As) than less extemporaneous (i.e., management discussions).

2.2 Capital market consequences of disclosure tone and its cultural component

Holding culture aside, the literature has examined the association between our disclosure attributes of interest and measures of economic performance. The positive association between the tone of earnings announcements and short-window stock returns around those announcements is a well-documented empirical regularity in the U.S. (Henry 2008; Davis et al. 2014; Demers and Vega 2014; Huang et al. 2014). ${ }^{7}$ This suggests that disclosure tone is incrementally informative about firm performance beyond the earnings surprise. Another strand of the literature examines the capital market implications of individualism. ${ }^{8}$ It follows from the two largely independent literatures that the capital market implications of disclosures are likely to vary along cross-country cultural differences.

\footnotetext{
${ }^{7}$ While the literature examines the decisions of overconfident investors, we are not aware of any studies that examine the stock market implications of managers' self-referential disclosures and apologies. Therefore, we limit our capital market tests to tone as the disclosure attribute of interest.

${ }^{8}$ Using individualism as a proxy for overconfidence and self-attribution bias, Chui et al. (2010) find a positive association between country-level individualism and (i) trading volume, (ii) volatility, and (iii) momentum profits and conclude that their results are likely consistent with a behavioral explanation for cross-country variation in momentum profits. Eun et al. (2015) document higher firm-specific stock return variation in individualistic countries, which they attribute to analytical thinking styles and less herding in those countries. Lastly, Pevzner et al. (2015) document a positive association between unsigned market reactions to earnings announcements, as measured by abnormal trading volume and return variance, and country-level individualism.
} 
Our baseline prediction is that disclosures with a more positive tone elicit higher stock returns, holding the underlying earnings news constant. If $\mathrm{H} 1$ holds, then the implication is that firms whose managers come from a less individualistic background are penalized: for a given piece of news, their disclosures are less optimistic, which would lead to lower stock returns. However, another possibility is that the capital market consequences of disclosure attributes vary with culture. That is, the same level of optimism may elicit higher or lower belief revisions depending on the individualism of both the speaker (managers) and the audience (investors). For example, investors may misinterpret the tone of a manager from a relatively collectivist background as implying worse news than they would from a manager from a more individualistic background, even if the earnings surprise were the same for both. Given the limited guidance from theory and prior literature, we do not form a hypothesis in that regard. Instead, we leave the association between stock returns and the interaction between individualism and tone as an empirical question.

\section{Sample and empirical measures}

3.1. Sample selection and classification of managers by their ethnic groups

Our primary data source for conference call transcripts is Thomson StreetEvents. Additionally, we obtain from Factset the transcripts of calls held by East Asian firms that do not subscribe to StreetEvents. This adds up to a cross-country sample of calls from 5,321 unique firms domiciled in 42 different countries.

Table 1 shows the details of the sample selection process for the earnings conference calls. We include all call transcripts between 2002 and 2012, subject to some minimal constraints. We require the calls to occur within the three days around an earnings announcement and we drop calls from countries with fewer than 30 observations during our sample period. We drop calls with a length in the bottom $5 \%$ of our sample, as measured by the total number of words. This ensures 
that our measures are based on dialogues with sufficient text. We drop calls that use translators because the tone of the original message may get lost during the translation process. Finally, we require firms to have financial data: total assets (WC02999), net income (WC01706), common equity (WC03501), and total debt (WC03255) from Worldscope and daily price (RI), volume (VO), and market value (MV) data from Datastream. Our final sample consists of 57,740 conference calls held by 5,021 unique firms.

The unit of observation in our main tests is a manager-conference call. Conference call transcripts in StreetEvents and Factset identify call participants every time they speak. Using all corporate managers (primarily CEOs, CFOs, but also COOs, CMOs, IROs, etc.) who speak during the Q\&A portion of our sample calls, our sample includes a total of 129,787 manager-conference call observations with 24,901 unique individuals.

To assign each individual to their most likely ethnic group, we collect the managers' first and last names directly from the conference call transcripts. We then map the names into ethnic groups using the ethnicity-name matching technique developed by Kerr (2008). ${ }^{9}$ The matching process exploits the fact that people with particular first names and surnames are likely to be of a certain ethnicity. The matching process uses both first names and surnames, however, it gives priority to surnames. ${ }^{10}$ The underlying pool of ethnic names is based on the database of two marketing companies that developed it to use in direct-mail advertisements. ${ }^{11}$ The technique classifies each name into nine distinct ethnic groups: Anglo-Saxon, Chinese, European, Hispanic,

\footnotetext{
${ }^{9}$ Alternatively, managers' nationality can be used to identify their ethnic group. However, information on nationality is missing for a large portion (more than $70 \%$ ) of our sample. Also, nationality can later be altered for naturalized managers, adding measurement error to the capture of cultural influence.

${ }^{10}$ Thus, the assignment came through the first names when a surname was not matched, or matched to several ethnicities.

${ }^{11}$ The first was developed by the Melissa Data Corporation, the second by List Services Direct, Inc.
} 
Indian, Japanese, Korean, Russian/Slavic, and Vietnamese. Appendix A discusses how we applied the matching process to the conference call sample in greater detail.

Table 2, Panel A shows the distribution of the managers in our sample by ethnic group. Two thirds $(=16,831 / 24,901)$, of the managers in our sample are classified in the Anglo-Saxon ethnic group. Western Europe (EUR), Hispanic (HIS), and Indian/South Asian (IND) are the next largest ethnic groups. Anglo-Saxon managers make up a large portion of our sample because (i) a majority $(111,071 / 129,787=85.6 \%$, based on the first column of Panel B) of the firms in our sample are located in Anglo-Saxon countries (i.e., Australia, Canada, New Zealand, the U.K., and the U.S.) and (ii) firms tend to hire local managers whose ethnic background matches that of the region where the firm is located (78\% for Anglo-Saxons, $74 \%$ for the full sample).

Table 2, Panel B shows the distribution of managers' ethnic group within each of the firms' ethnic regions. The table is structured so that each row (i.e., each firm's ethnic region) adds up to $100 \%$. The high percentage in the diagonal of the matrix indicates that most firms hire managers within their own ethnic region. The figures range from $48 \%$ (for EUR) to $78 \%$ (for ENG), suggesting that most firms tend to hire managers with an ethnic background that matches the firm's. However, there is still substantial variation in managers' ethnic groups (i.e., the offdiagonals). For example, for firms domiciled in Anglo-Saxon countries (i.e., Australia, Canada, New Zealand, the U.K., and the U.S.), 78\% of their managers are Anglo-Saxon, 13\% are European, and 3\% are Hispanic. We use off-diagonal observations to test our second and third hypotheses, and to check the robustness of our results in a single-country setting (the U.S.)

Table 2, Panel C shows the distribution of managers' ethnic groups by years. The number of managers shows a steady increase from 2002 to 2012. The dominance of Anglo-Saxon managers is more pronounced in the earlier years (i.e., $81 \%$ in 2002) but shows a steady decrease throughout 
our sample period (i.e., 69\% in 2012). Representation of other non-Anglo-Saxon ethnic groups, especially Hispanic (HIS), Indian/South Asian (IND), and Chinese (CHN), shows a steady increase throughout our sample period.

\subsection{Measures of individualism}

We measure the degree of individualism stemming from our sample managers' cultural ethnicity using Hofstede's (2001) individualism index. The index comes from a cross-country survey of employee values conducted between 1967 and 1973. The subjects of this survey were approximately 88,000 IBM employees in 72 countries. The individualism index was calculated from the country mean scores on 14 questions about the employees' attitudes toward their work and private lives. ${ }^{12,13}$ Hofstede's measure has been validated, and used extensively in prior studies, including Chui et al. (2010) in the finance literature; Schultz et al. (1993) and Kachelmeier and Shehata (1997) in the accounting literature; and Franke et al. (1991), Yeh and Lawrence (1995), and Weber et al. (1996) in the economics literature.

Hofstede's measure is a country-level variable. However, each of the seven ethnic groups we obtain from Melinda's classification scheme spans several countries. We therefore aggregate the individualism index to map into each ethnic group, using the average of the individualism index of all countries that belong to the ethnic group. We weigh the measure by the number of firms in each country (using our conference call sample). For example, to calculate the

\footnotetext{
${ }^{12}$ Factor analysis was used to analyze the country mean scores on 14 work-goal questions and two factors were produced. The individualism index is constructed from the scores based on the first factor, which is highly correlated with 6 out of 14 work questions. The six questions include the following: (i) Have considerable freedom to adapt your own approach to the job; (ii) Have challenging work to do: work from which you can get a personal sense of accomplishment; (iii) Have a job which leaves you sufficient time for your personal or family life; (iv) Have training opportunities; (v) Have good physical working conditions; and (vi) Fully use your skills and abilities on the job (Hofstede 2001, p.256).

${ }^{13}$ Holfstede's measures were based on a survey of IBM employees which may not be representative of cross cultural differences found outside of IBM. Several studies administered the questionnaires in other settings, using members of government and business leaders (Hoppe 1990), employees (Shane 1995), and consumers (deMooij 2001). All these studies were able to replicate the individualism measures of Hofstede.
} 
individualism index of the Anglo-Saxon ethnic group, we average the individualism index of all countries where the dominant ethnicity is Anglo-Saxon (i.e., Australia, Canada, New Zealand, the U.K., and the U.S.), weighted by the number of firms in each country. The countries included in each ethnic group are from Kerr (2008) and can be found in Table 2. We scale the individualism measure by 100 and present the measure in percentage terms.

Table 2 shows the individualism measure for each ethnic group. The ethnic group with the highest individualism measure is Anglo-Saxon, followed by European. Groups with a lower individualism measure are the South Korean and the Chinese. Japan scores highest on individualism among the East Asian countries. ${ }^{14}$ Overall, the ranking is consistent with findings in the psychology literature (Chang 2001).

\subsection{Measures of disclosure attributes}

We use three measures of disclosure attributes, which we expect to vary with managers' cultural background. All measures are at the manager-call level. To construct the measures, we use all the answers of each manager during the Q\&A session of a given conference call. The first one is tone, which we measure according to prior literature. Using the dictionary from Loughran and McDonald (2011), we count positive and negative words separately for each participant. We label the difference between positive and negative terms scaled by the sum of positive and negative words as Tone. Second, we count the number of times a manager uses singular first-person pronouns ("I", "me", "my", "mine", "myself"), scaled by total words spoken by the manager (SelfReference). ${ }^{15}$ Our third disclosure attribute measure is the degree to which managers tend to

\footnotetext{
${ }^{14}$ Hofstede (2001) explains that while "Japanese society shows many of the characteristics of a collectivistic society: such as putting harmony of group and people have a strong sense of shame for losing face, it is not as collectivistic as most of her Asian neighbors. [The Japanese] are more private and reserved than most other Asians." (http://geerthofstede.com/japan.html)

${ }^{15}$ The construct differs from self-attribution, which refers to attributing only favorable performance to internal causes and poor performance to external causes ( $\mathrm{Li} 2012$; Kimbrough and Wang 2014). We consider managers' tendency to
} 
apologize (Apologies). To measure Apologies, we count the number of times a manager says "sorry" or "apolog*", and scale by the number of words used by the managers during the call.

Table 3, Panel A reports descriptive statistics for the four disclosure attributes. The mean and median Tone_Q $Q A$ indicate that, on average, managers use more positive than negative words. This is consistent with studies based on U.S. data (Davis et al. 2015). The mean SelfReference_$Q \& A$ is 1.52 , and the mean Apologies_ $Q \& A$ is 0.02 . The median and third quartile are equal to zero, suggesting some skewness in the data, as most managers do not use apologetic words in their answers. Additionally, we report descriptive statistics for the disclosure attributes measured during the MD portion of the conference calls (also measured at the individual executive level). We later use those measures for comparison, since the effect of culture should be weakerif not muted—during scripted management discussions.

Going back to Table 2, Panel A, where the mean disclosure attributes are reported separately by ethnicity, some patterns emerge. Tone tends to be more positive, and apologies less frequent, for ethnicities that are considered more individualistic. Since those descriptive statistics do not take into account differences in terms of underlying news, we design regression tests to examine our hypotheses in the next section.

\section{Empirical tests and results}

4.1 Disclosure attributes and individualism: Manager-level analysis

We start out by examining whether cultural background (i.e., individualism) based on a manager's ethnicity affects disclosure attributes. More specifically, we test whether managers from

use singular first-person pronouns in all situations regardless of whether the news is favorable or not. In other words, the tendency to use singular pronouns does not need to be self-serving. Gow et al. (2015) also count singular and plural first-person pronouns in earnings conference calls, and refer to them collectively as self-reference. We only focus on singular pronouns, as plural ones reflect greater collectivism. 
more individualistic ethnic groups use a more optimistic tone, make fewer apologies, and use more singular first-person pronouns in their disclosure narratives (hypothesis 1). We use the following regression model with managers indexed as $m$, firms as $i$, and call quarters as $t$ :

Disclosure attributes (Tone_Q $\& A$, Self-reference_Q $Q A$, Apologies_Q $Q A)_{m, i, t}$ $=\alpha_{0}+\beta_{1}$ Individualism $_{m}+\sum \beta_{j}$ Manager control $_{j, m, t}+\sum \beta_{k}$ Conference call control $_{k, i, t}$ $+\sum \beta_{l}$ Firm control $_{l, i, t}+\sum \beta_{n}$ Country control $_{n, i, t}+$ Industry FE Year FE $+\varepsilon_{m, i, t}$

The unit of analysis is manager $(m)$ in calls of firm $i$ in quarter $t$. The dependent variables are the three disclosure attributes discussed earlier in section 3.3, measured at the individual manager level.

Individualism $m_{m}$ is the individualism index of manager $m$. As discussed in section 3.2., the measure varies by ethnic group and takes higher values for groups that have a more individualistic culture. $\beta_{1}$ is our main variable of interest; it captures the effect of a manager's individualism on his/her disclosure attributes. The individualism measure is identified based on the manager's ethnicity rather than the ethnic region where the firm is domiciled. This is because the behavioral attributes we examine are fundamentally an innate individual-level construct.

We control for managerial characteristics that are known to affect disclosure policies (Davis et al. 2015). We include the executive's gender, age, and educational background (Degree). We also include an indicator for CEOs ( $\mathrm{Li}$ et al. 2014). Data on managerial characteristics are obtained from BoardEx by matching each individual-firm pair using first and last names. ${ }^{16}$ Additionally, we control for other properties of managers' speech that are potentially correlated with their ethnic background and our disclosure attributes of interest. We use two measures of linguistic opacity, Plain English and Grammar Errors, which Brochet et al. (2016) find to be associated with the language distance between managers' country of origin and English. Not all

\footnotetext{
${ }^{16}$ Availability of such information in BoardEx is limited for firms outside the U.S. We therefore supplement the BoardEx data with internet searches (e.g., LinkedIn).
} 
managers in the sample are native English speakers, and their choice of words in terms of tone, apologies or self-referencing may be a manifestation of their language barriers.

We include various conference-call- and firm-level determinants of the level of transparency in the disclosure narratives. The count of total words (Words) and the number of analysts participating in the call (Participation) proxy for the amount of information released and the level of interest in the marketplace for the call, respectively. Firm size (Size), profitability $(R O A)$, Tobin's $\mathrm{Q}(Q)$ and Leverage proxy for various dimensions of business complexity, whereas the number of analysts covering the firm in $\mathrm{I} / \mathrm{B} / \mathrm{E} / \mathrm{S}$ ( Log Analysts) accounts for differences in the information environment driven by the demand side. The disclosure tone may also change with the properties of reported earnings and anticipated economic news. We control for the underlying earnings news using earnings surprise $(E S U R)$, measured as the difference between the actual annual EPS minus the most recent mean analyst forecast (if available, a seasonal random walk model otherwise) scaled by price. We also include a loss dummy (D_loss) for firm-quarters with negative earnings and the stock returns during the fiscal year (Ret_fye). We also control for any fiscal year end effect using an indicator for calls held in the fourth quarter (year_end).

Finally, we include various cultural, economic and institutional country-level determinants that may affect managers' disclosure attributes. We include other dimensions of culture (Uncertainty avoidance, also from Hofstede (2001), and Lack of trust, from World Value Surveys) that have been shown to affect corporate policies (Pan et al. 2015). We include financial development measures using the log of equity market capitalization (Market Cap) and the annual changes in the market index (Market Return). We include price synchronicity (Synchronicity) and Zero Returns to account for the transparency and liquidity of the information environment and the rule of law index (Law) to control for quality of institutions. All country-level controls are adjusted to reflect the ethnic region 
of the individual using the method discussed in section 3.2. Alternatively, we restrict our sample to the U.S., thereby excluding country-level variables from the regression. Finally, we include year and industry fixed effects to account for unobserved factors that may affect disclosure attributes over time and across industries. Detailed definitions of each variable are provided in Appendix B.

Table 3 presents descriptive statistics for the variables included in the study. The results from Panel B indicate that $6 \%$ of the managers in our sample are female and $10 \%$ have a post-graduate education. The average age is 52.77. The call and firm characteristics indicate that our sample consists of large firms with significant participation by managers (a mean of 1,041 words spoken by call/manager) and analysts (median of $7\left(=\mathrm{e}^{1.95}\right)$ participants per call). We next present the estimated coefficients from our regression model in equation (1). We estimate the model using ordinary least squares (OLS) and cluster the standard errors by firm and by year. Table 4 presents the results.

Table 4, Panel A shows that a manager's individualism is positively associated with $T o n e \_Q \& A$ and Self-Reference_Q $Q \& A$, and negatively associated with the use of apologies (Apologies_Q\&A). The estimated coefficient on Individualism is positive and significant, 0.091 (tstat=4.51) using Tone_Q $Q A$ in column 1 . The results indicate that a one standard deviation increase in individualism $(=0.20$, Table 3 Panel $\mathrm{B})$ is associated with a 0.018 higher Tone_Q $\& A$. With our second disclosure attribute, Self-reference_Q $Q \& A$, as the dependent variable in column 2, we also find a positive and significant coefficient of 0.174 ( $t$-stat=4.47). For the apologies measure, we find a negative association between the level of managers' individualism and the use of apologies $\left(\beta_{1}=-\right.$ 0.015, t-stat=-6.20), as per column 3. To compare the economic significance of the coefficients, we rerun the three regressions with standardized variables. The results indicate that a unit change in standardized individualism (a one standard deviation in individualism) is associated with a $3.5 \%$ 
higher standardized tone, $3.6 \%$ higher standardized self-reference, and $4.1 \%$ fewer standardized apologies (not tabulated).

Other manager characteristics exhibit significant associations with the disclosure attributes we examine. CEOs tend to speak more positively, use more singular first-person pronouns, and apologize less, on average. Female managers use less optimistic language and apologize more, consistent with women being less prone to overconfidence (Barber and Odean 2001). Older managers use more pessimistic tone, but they use more singular first-person pronouns, and apologize less. Several conference call and firm characteristics exhibit significant associations with disclosure attributes. Managers from larger firms use more pessimistic language but use more singular firstperson pronouns. As expected, managers use more optimistic tone when stock returns are higher, when they report profits and positive earnings surprises.

In Table 4, Panel B, we restrict the sample to conference calls held by U.S. firms, in order to minimize the possibility that our results could be driven by unobserved country characteristics. All control variables - except for country characteristics - are included but not tabulated for succinctness. We find patterns consistent with the cross-country sample: Managers of U.S. firms who are from a relatively more individualistic ethnic background exhibit more positive tone (column 1), self-reference (column 2), and make fewer apologies (column 3). The coefficients of interest are statistically significant at the 0.01 level. Overall, the primary takeaway from Table 4 is that cultural background based on an individual's ethnicity affects the disclosure attributes after controlling for other determinants of country-, firm-, and manager-level characteristics.

4.2. Persistence of the effect of cultural individualism on disclosure attributes: Cross-cultural experience 
Next, we examine individuals who are exposed to cultures outside their inherited ethnic region. If inherited ethnic culture is long lasting, the disclosure attributes of executives will continue to show patterns consistent with their inherited cultural backgrounds, even for individuals who are exposed to different cultural environments. If the culture acquired through subsequent organizational practices dominates the individual's inherited ethnic culture, the disclosure attributes of individuals with cross-cultural experience may no longer show influences of the manager's inherited ethnic culture. Our hypothesis is that managers exposed to different cultures express themselves in a way that is in between those two scenarios. That is, their ethnic culture influences their disclosure attributes, but less so if they are subsequently exposed to a different culture (H2).

To test this hypothesis, we separate our sample between local managers and those with cross-cultural experience. Managers are classified as local if their ethnicity matches that of the dominant ethnicity in the country where their firm is headquartered (i.e., if they are on the diagonal in Table 2, Panel A), and cross-cultural (i.e., off diagonal) otherwise. In both samples, $\beta_{1}$ is the coefficient of interest. The $\beta_{1}$ coefficients in the local manager sample form a base-line estimate of the effect of ethnic cultural. Our interest is twofold: First, is $\beta_{1}$ positive and significant in the cross-cultural sample? That would suggest managers' inherited individualism continues to affect their disclosure, even if they are exposed to organizational cultures outside of their cultural upbringing. Second, according to $\mathrm{H} 2$, we expect $\beta_{1}$ to be significantly greater (more negative for apologies) in the local than in the cross-cultural sample.

Table 5, Panel A shows the estimated coefficients for the full sample, 74\% of which consists of local managers. The coefficient on Individualism is positive and significant when the dependent variable is Tone_Q $Q \& A$, both for local and cross-cultural managers (columns 1 and 2). 
However, the effect for local managers $(=0.273)$ is significantly larger than for cross-cultural ones $(=0.092)$, as per the F-test $(\mathrm{p}=0.02)$. Hence, while managers' inherited cultural individualism still matters in shaping their disclosure tone once they are exposed to a different culture, the effect is partly muted, consistent with $\mathrm{H} 2$. Similar to Tone_Q\&A, Self-Reference_$Q \& A$ is positively and significantly associated with Individualism in both samples, ( 0.372 for local managers, 0.162 for cross-cultural managers), but with no significant difference between the two samples ( $\mathrm{p}=0.27$ for the F-test). A similar pattern emerges with Apologies_ $Q \& A$ as the dependent variable, and the Ftest also rejects the null of equality between the two coefficients.

Hence, a mixed picture emerges from Table 5, Panel A. Judging solely from the coefficients on the disclosure attributes in the cross-cultural sample, managers' inherited cultural background persists in shaping their disclosure attributes. The comparison with local managers indicates that the effect is partly muted when managers are exposed to a different culture, but only significantly so for tone. This result suggests that while inherited culture has a lasting effect, neither inherited nor acquired culture "dominates" the other per se.

To maintain the approach used in Table 4, we also report results based on the U.S. sample in Table 5, Panel B. However, we can only report cross-cultural ones, since there is no within-country variation in Individualism for local managers. Consistent with the full sample, we find that crosscultural (i.e., non-Anglo-Saxon) managers who work for U.S. firms exhibit a positive (negative) and significant association between their inherited cultural background in terms of individualism, and their disclosure tone and self-reference (propensity to apologize). Overall, the results in Table 5 indicate that the effect of inherited culture on disclosure attributes persists for managers that work 
for firms located in regions where another culture dominates, but the effect on tone and self-reference is partly diluted. ${ }^{17}$

4.3. Variation in disclosure attributes within firms with high ethnic diversity: Firm-level analysis The results thus far indicate that individual managers speak during conference calls in a way that reflects their cultural background. We next examine whether culturally diverse management teams exhibit greater within-firm variation in their disclosure attributes. If a managers' tone remains unaffected by others in the management team, firms with a diverse ethnic team will show greater within-firm variation in the tone among managers. Our results indicating that the effect of inherited culture on a manager's disclosures survives exposure to other cultures suggests this should occur. However, it is also possible that the hiring/training process of top managers is such that managers are made to speak in ways that is more consistent with the overall tone of the management team. We use the following model to address that question:

$$
\begin{aligned}
& \text { Standard Deviation of Disclosure attributes (Tone, Self-reference, Apologies) })_{m, i, t} \\
& =\alpha_{0}+\beta_{1} \text { Ethnic Diversity }_{m}+\sum \beta_{k} \text { Conference call control }_{k, i, t}+\sum \beta_{l} \text { Firm control }_{l, i, t} \\
& +\sum \beta_{n} \text { Country control }_{n, i, t}+\text { Industry FE }+ \text { Year FE }+\varepsilon_{m, i, t} .
\end{aligned}
$$

The unit of observation is a firm-year. The dependent variable is the standard deviation of the disclosure attributes measured at the manager-level within each firm-year. The main variable of interest, Ethnic Diversity, indicates firm-years with at least one manager whose ethnicity does not match that of the rest of the team. If individual managers' cultural ethnicity results in disclosure attributes that reflect more idiosyncratic style, then we should observe a more dissonant message

\footnotetext{
${ }^{17}$ Managers can also be exposed to different cultures through their education. In untabulated analysis, we examine the effect of inherited versus acquired culture on managers' disclosure for managers who studied at a university/institution located in a country where the dominant culture differs from that of their ethnicity, and 'local' otherwise we find that managers with cross-cultural educational background exhibit a weaker association between their inherited culture and disclosure patterns. This suggests either that those who self-select into studying abroad are less influenced by their home culture to begin with, or that exposure to different cultures in an academic environment has some mitigating effect on the cultural dimension of disclosure choices.
} 
in ethnically diverse teams. That is, the coefficient on Ethnic Diversity should be positive. Compared to the manager-level tests, we also add stock return and earnings volatility, and the magnitude of accruals as controls. All three measures capture dimensions of uncertainty, which should be positively associated with dispersion in managers' disclosures.

Table 6 reports the results of the OLS estimates of Model (2). In the first column, the dependent variable is the standard deviation of tone. The coefficient on Ethnic Diversity is positive (0.033) and significant $(\mathrm{p}<0.01)$. Hence, ethnically diverse management teams exhibit more dispersion in their disclosure tone. In terms of economic significance, having a diverse management team leads to an $8 \%(=0.033 / 0.43)$ increase in the standard deviation of tone relative to the sample mean. We find qualitatively similar results with self-reference and apologies. There is significantly greater dispersion in self-reference and apologies among ethnically diverse teams than homogenous ones. ${ }^{18}$ Panel B repeats the analysis using U.S. firms only. The results largely echo those of Panel A. Altogether, the results in Table 6 suggest that the effect of cultural ethnicity on managers' disclosure attributes leads to more within-firm dispersion in disclosure attributes when management team members hail from different cultures. Hence, culture appears to affect not only the first but also second moment in disclosure attributes.

\subsection{Management discussion (MD) portions of the calls}

The analysis thus far is based on managers' answers to analysts' questions during conference calls. As discussed in $\mathrm{H} 3$, we expect the level of spontaneity of those extemporaneous disclosures to reveal the effect of culture on managers' word choices. In contrast, the likely more scripted (and

\footnotetext{
${ }^{18}$ In additional analysis (untabulated), we repeat the test using the management discussion section of the calls. We find that the effect of ethnic diversity is positive and significant $(0.022=$ for presentation tone, $t-s t a t=7.116)$ but the magnitude of the coefficient is smaller than the 0.033 for the Q\&A section (p-value of F-test $=0.0123$ ). The findings suggest that there are stronger institutional forces in the presentation sections which can mute the effect of an individual manager's ethnic background and promote a tone that is more homogeneous across the management team.
} 
even created by a group of individuals other than the speaker) MD portion of the call should exhibit less (or no) variation due to managers' individual culture. We test H3 by estimating Model (1) based on managers' speech during the MDs. For completeness, we also test whether the overall effect of culture persists or is muted once we combine the MD and Q\&A.

Table 7 reports the results. In Panel A, the sample includes all countries. For each disclosure attribute, we report three regression results: The Q\&A (identical to Table 4), the MD, and the entire call. For Tone_MD, the coefficient on Individualism is negative and significant $(=-0.0065, \mathrm{t}-\mathrm{stat}=-$ 3.719) during the MD. This is in sharp contrast to the positive coefficient $(=0.091, t-s t a t=4.507)$ in the Q\&A. It suggests that managers go against their cultural background (or are coached to do so) in the prepared MD. On balance, the insignificant coefficient on Individualism in the third column suggests that the cultural component of tone is muted when the entire conference call is taken into account.

Similarly, for Self-reference_MD the coefficient on Individualism is negative $(=-0.028, \mathrm{t}-$ stat=-0.938) in column 5, although insignificant. That is, we find no evidence that managers from more individualistic culture self-refer more during the MD. When we combine the MD and the Q\&As, the cultural influence of self-referencing persists even after taking the MD into account, as indicated by the marginally significant coefficient on Individualism $(=0.054$, t-stat $=1.779)$ in column 6. Lastly, as per the negative and significant coefficient on Individualism $(=-0.001$, t-stat=-2.460) in column 8, culturally individualistic managers also apologize less frequently during MDs. While consistent with the Q\&A results, the coefficient is much smaller than in column 7. Regardless, the cultural component of Apologies endures when measured over the entire call (column 9). Overall, the effect of cultural individualism on disclosure appears to be either muted or reversed during MDs, where managers' individual characteristics are less likely to come through. 
We also run the analysis for U.S. firms only in Panel B. Several noteworthy results emerge. First, the coefficient on Individualism for Tone_MD, in column 2 remains negative. Hence, the result in Panel A is not solely due to firms/managers from collectivist culture injecting more positive tone in their management discussions. The results hold even within a single country-level institutional environment. In other words, our findings cannot be explained by other cross-country differences (e.g., litigation risk) that may differentially affect disclosure outcomes (Rogers et al. 2011).

Second, in column 5, the coefficient on Individualism is positive and significant, suggesting that U.S. managers are more likely to self-refer during MDs as well. Lastly, Individualism does not have a statistically significant bearing on U.S. managers' propensity to apologize, as per column 8 . Altogether, the results in Table 7 indicate that during MDs, managers do not express themselves in a way that reflects their cultural individualism, consistent with $\mathrm{H} 3$. The contrasting results between Q\&As and prepared remarks suggest that managers and/or firms are not entirely passive vis-à-vis the effect of culture on word choice.

\subsection{Capital market tests}

Having established that disclosure attributes vary with managers' cultural backgrounds, we next examine how listeners-i.e., investors-respond to the disclosure patterns of managers from different cultural backgrounds by examining stock returns during conference calls. We focus on tone as our variable of interest, because its association with firm performance is least ambiguous, and has been examined in the U.S. (e.g., Huang et al. 2014). We use intraday data to examine the market responses separately for the MD and the Q\&A section. Thus, we limit the analysis to U.S. firms, for which the TAQ database provides intraday data.

We use the following regression model to test the investors' reaction to the calls:

$$
\begin{aligned}
& \text { CAR }_{i, t}=\alpha_{0}+\beta_{1} \text { Tone }_{i, t}+\beta_{2} \text { Tone }_{i, t} \times \text { Low Individualism }+\alpha_{1} \text { Low Individualism }
\end{aligned}
$$

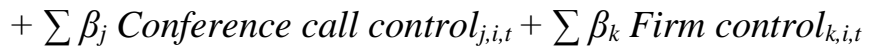

$$
\begin{aligned}
& +\sum \beta_{l} \text { Country control }{ }_{l, i, t}+\text { Industry FE }+ \text { Year FE }+\varepsilon_{i, t .}
\end{aligned}
$$


Subscripts $i$ and $t$ indicate firms and quarters, respectively. One challenge with the capital market test is that we can only measure market reactions at the firm-level whereas the disclosure attributes used so far were constructed at the manager-level. We modify the disclosure measure by aggregating it across executives who speak during a firm $i$ call in quarter $t$ (or during the portion of interest). Hence, Tone is now defined as the positive minus negative words of all managers that spoke during the call scaled by the total number of positive and negative words.

The dependent variable is the market-adjusted return (CAR) during the conference call, or a portion thereof (Q\&A or MD, depending on the specification). We estimate the start and end times of the call and portions thereof using the methodology described in Matsumoto et al. (2011). Transcripts from StreetEvents and Factset include time stamps for conference call starts. Matsumoto et al. (2011) estimate that, on average, the introductory remarks last 116 seconds, while the MD and Q\&A lengths can be inferred from a pace of 160 and 157 words spoken per minute, respectively.

We expect a positive $\beta_{2}$ : The more positive the tone, the higher the return during the call. Our variable of interest is the interaction between tone and the low individualism indicator, which equals one if the firm's mean individualism is above the country's median individualism. We make no prediction for the sign, but note that if investors give more credence to the positive tone of managers from more collectivist ethnic groups, we would observe a stronger response to the tone of firms with more managers from a collectivist ethnic group. As in the determinants test, we control for call-, firm-, and country-level characteristics that have been shown and/or are likely to be associated with stock returns and analyst forecast revisions around earnings announcements and conference calls. The most important controls are the earnings surprise, and the indicator for 
negative earnings. Both will be correlated with the dependent variable and the independent variables of interest.

Table 8 Panel A reports the results from the OLS estimation of Model (3) using all countries in the sample. The first two columns present results using returns during the Q\&A session as the dependent variable. In column 1, the coefficient on Tone is positive and statistically significant $(=0.15, \mathrm{t}-\mathrm{stat}=2.80)$, which indicates that conference call Q\&As with a more positive tone elicit higher short-window stock returns. The findings suggest that a one standard deviation increase in tone $(=0.51$, Table 3$)$ is associated with 8 more basis points. This holds after controlling for the positive effect of the earnings surprise, and the negative effect of negative earnings. However, when we add an indicator for less individualistic managers (Low Individualism Indicator) and its interaction with tone, we do not find an incremental effect, as per the insignificant coefficient on Tone_Q\&A*Low Individualism in column 2. A similar pattern emerges during the MD portion of the call. The coefficient on Tone_MD is positive and significant $(=0.10$, t-stat $=2.49)$, but not on the interaction with Low Individualism. Consistent with the separate Q\&A and MD results, the combined return/tone association is positive and significant, but does not differ based on the cultural background of the management team. Hence, we fail to find evidence that investors adjust for cultural differences in tone when reacting to earnings conference calls.

\section{Additional tests}

5.1. An alternative measure of individualism and other robustness tests

In this section, we examine whether our findings hold once we use an alternative measure of individualism attributable to genetic transmission. Following prior economic studies on individualism, we use differences in blood type prevalence across ethnicities as a proxy for a 
genetic-based mechanism of cultural transmission (Gorodnichenko and Roland 2010, 2011). These

studies argue that because blood type is a neutral genetic marker, i.e., one that has no effect on other attributes of individuals, it captures the genetic component of culture that is independent of other social transmission channels. ${ }^{19}$

Following this literature, we create a measure of individualism that can be explained by the variation in blood type differences across ethnic groups. More specifically, we construct a measure of Blood Type Distance, the Euclidian distance between the blood type mix of an ethnic group and that of Anglo-Saxons, the most individualistic ethnicity in our sample. We obtain ethniclevel blood type data from Cavalli-Sforza et al. (1994). In our first-stage model, the coefficient on Blood Type Distance is negative and significant, indicating that ethnicities with a blood type mix that is more distant from that of the Anglo-Saxon population exhibit less individualism. Furthermore, with an $\mathrm{R}^{2}$ of $80 \%$, the first stage estimates (untabulated) indicates that our measure of genetic-based mechanism of cultural transition is strongly correlated with individualism.

We re-run our main analysis by replacing Individualism with its predicted value from the first stage. Table 9, Panel A, reports the results. In terms of sign, magnitude, and statistical significance, the coefficients on Predicted Individualism are consistent with the OLS results. That is, executives with higher predicted individualism attributable to their ethnicity's blood type use more optimistic tone, greater self-reference, and make fewer apologies. This suggests that our findings hold when we use only the genetically-transmitted component of culture.

\footnotetext{
${ }^{19}$ Gorodnichenko and Roland $(2010,2011)$ use this variable as an instrument arguing that blood type satisfies the exclusion restriction criterion because it is a neutral genetic marker, i.e., one that has no effect on attributes that should impact financial economic outcomes. Subsequent studies, however, challenge the validity of this instrument because genetic composition may be correlated with variables other than ethnic cultures, which may affect the outcome variable (Giuliano et al. 2013). We also note that this is a difficult — if not impossible — claim to ascertain. If individuals inherit traits genetically and culturally from their parents in ways that are highly correlated, then the impact of culture on disclosure is not distinguishable from that of genes. Hence, our two stage tests may be more conservatively interpreted as being based on blood type as an alternative measure of individualism to that of Hofstede.
} 
Another potential concern with manager-level analyses is the possibility that unobserved firm-level factors drive the observed association between manager characteristics and the outcome of interest. We supplement our tests using firm fixed effects and a change instead of level specification.

Under the firm fixed effect specification, the coefficient on Individualism will capture within-firm (but across-manager) variation in disclosure attributes due to managers' cultural background. The results are tabulated in Table 9, Panel B. In terms of sign and statistical significance, the coefficients on Individualism remain generally robust to the inclusion of firm fixed effects. In terms of magnitude, the coefficients are generally smaller than in Table 4, Panel A. Nevertheless, the results indicate that within a given firm, managers from a more individualistic ethnic background use more optimistic tone, and apologize less than those from a more collectivist background.

Under the change specification, using firm-quarter data, we take within-firm first differences (compared to the previous call) in all variables of interest (disclosure attributes and individualism of the management team) and controls that also vary over time. AIndividualism will vary if the management teams ethnic mix changes from one call to another, primarily due to executive turnover. The results are tabulated in Table 9, Panel C. In columns 1 and 3, the coefficient on AIndividualism is positive (negative) and significant: when the management team is ethnically more individualistic than in the previous call held by the same firm, tone is significantly higher, and apologies lower. Although positive, the coefficient on Self-reference is not significant. We obtain similar results when we only keep observations with non-zero changes in individualism (not tabulated). 
Finally, we test whether the effect of culture on disclosure attributes persists across good and bad news partitions. An underlying assumption in our hypothesis is that the effect of individualism on a manager's disclosure attributes stems from inherited cultural traits. If so, we would expect the effect to persist even if the manager is exposed to situational forces that could lead him/her to deviate from this cultural norm. However, it is possible that managers' disclosure incentives vary depending on whether they communicate good or bad news, especially when it comes to self-attribution (Kimbrough and Wang 2014). We repeat our earlier analysis in Table 4 by looking at positive and negative earnings surprises separately. Earnings surprise is defined as the difference between the actual annual EPS minus the most recent mean analyst forecast, if available, or a seasonal random walk model otherwise.

Table 9, Panel D reports the results. Across all partitions, the coefficients are consistent with the full sample results. That is, Individualism is positively associated with Tone, and SelfReference, and negatively associated with Apologies, regardless of whether the earnings news is positive or negative. ${ }^{20}$ Furthermore, the coefficients are all statistically significant, and the F-tests indicate that we cannot reject the null of coefficient equality across good and bad news partitions. Hence, the effect of cultural individualism on disclosure attributes holds regardless of the underlying news, suggesting a persistent phenomenon.

\subsection{Measurement error}

We perform several robustness tests to further mitigate concerns related to measurement errors. First, we include indicators for managers whose names cannot be attributed with certainty to a unique ethnicity. The ethnicity-name matching algorithm yields a probability distribution of

\footnotetext{
${ }^{20}$ One could argue that individualistic managers should be less likely to use self-referencing language when earnings news is bad. However, our results do not support the view that self-referencing language is necessarily self-serving. Rather, the cultural dimension of self-reference appears to be an unconditional tendency to talk more in the first person or from the firm's standpoint.
} 
the matching ethnic groups based on the manager's first and surnames, giving priority to surnames. However, it is possible that two managers with the same surname are match to different ethnic origins. This occurs when the surname is not matched (or was matched with several ethnicities), and the assignments came through first names. ${ }^{21}$ To address the possibility that those may be erroneous matches, we create a variable based on the number of ethnicities that a given surname can be matched with in our sample (\# of Ethnicities). We include this variable and its interaction with Individualism in our tests. Table 10, Panel A, reports the results (control variables are included but not tabulated). We find that our main results remain qualitatively unaffected by the inclusion of \# of Ethnicities and its interaction with Individualism.

Measurement error can also occur with female managers who change their name through marriage and whose spouse is from a different ethnicity. To address this issue, we rerun our tests without female managers. Table 10, Panel B, reports the results (control variables are included but not tabulated). The results are robust to this exclusion.

Lastly, we further control for the disclosure attributes during the MD portion of the calls, where each speaker is also separately identified. For example, when a manager's Q\&A tone is on the left-hand side, that same manager's MD tone is added as a control on the right-hand side. Table 10, Panel C, reports the results. Across all disclosure attributes, the coefficient on the MD part is positive and significant. More importantly, the coefficients on individualism remain significant. ${ }^{22}$

\section{Conclusion}

We examine the effect of managers' cultural background on their disclosure narrative in the context of earnings conference calls. Using managers' ethnicity to infer their cultural

\footnotetext{
${ }^{21}$ Last names that are matched to more than one ethnic origin are less than $10 \%$ of our sample.
} 
upbringing, we test whether executives from a more individualistic (as opposed to collectivist) background speak in a more optimistic and self-confident manner during conference calls. Our sample consists of English-language conference calls held by firms from around the world.

Our primary finding is that managers from a more individualistic background use a more positive tone, more singular first-person pronouns, and make fewer apologies relative to managers from a collectivist ethnicity. The results are specific to the Q\&A portion of the conference calls, where individual managers' cultural roots are more likely to have an effect. In contrast, the cultural effect of inherited individualism is largely absent from the less extemporaneous MD part of the call, and even reversed in the case of tone. While we find that the inherited culture of managers who are exposed to another culture through work or education has a somewhat weaker effect on their disclosure tone, our tests otherwise indicate that the effect of culture on disclosure optimism and self-confidence is sticky, including across partitions on positive and negative earnings news.

Additionally, we find that firms with culturally diverse management teams exhibit greater dispersion in their disclosure across managers. This suggests that culture not only affects the first, but also the second moment of the distribution of firms' disclosure tone, managerial self-reference, and apologies.

Lastly, we provide some evidence on the capital market effects of disclosure attributes in a cross-country setting. We find that disclosure tone elicits more positive short-window stock returns around conference calls, and the effect of tone does not differ across culturally diverse and 'purely' local teams. Hence, the evidence suggests that market participants do not adjust their interpretation of disclosure tone for firm value based on the cultural background of the management team. 
Our results speak to the role played by culture in shaping corporate disclosure narratives. We add to and bring together several strands of literature that examine (a) the textual content of corporate disclosures and its capital market consequences and (b) the role of culture in explaining capital market outcomes. We also innovate beyond prior literature by using managers' ethnic background and a cross-country earnings conference call sample to perform our empirical tests. Our findings should prove useful to academic and practitioner audiences who wish to better understand cross-cultural patterns in corporate disclosures and their implications for the capital market. 


\section{References}

Alesina, A., and P. Giuliano., 2015. Culture and Institutions, Journal of Economic Literature. Forthcoming.

Barber, B. M., and T. Odean. 2001. Boys Will be Boys: Gender, Overconfidence, and Common Stock Investment. The Quarterly Journal of Economics 116 (1): 261-292.

Bertrand, M., Schoar, A., 2003. Managing with Style: The Effect of Managers on Firm Policies. The Quarterly Journal of Economics 118, 1169-1208.

Biais, B., Hilton, D., Mazurier, K., Pouget, S., 2005. Judgemental Overconfidence, Self-Monitoring, and Trading Performance in an Experimental Financial Market. Review of Economic Studies 72, 287-312.

Brochet, F., Naranjo, P.L., Yu, G., 2016. The Capital Market Consequences of Language Barriers in the Conference Calls of Non-U.S. Firms, The Accounting Review 91(4): 1023-1049.

Cavalli-Sforza, L. L., P. Menozzi, and A. Piazza. 1994. The History and Geography of Human Genes. Princeton University Press.

Chang, E. C., 2001. Optimism \& Pessimism: Implications for Theory, Research, and Practice, Washington, D.C.: American Psychological Association.

Chatterjee A. and D. Hambrick 2007. It's All About Me: Narcissistic Chief Executive Officers and Their Effects on Company Strategy and Performance. Administrative Science Quarterly 52: 351-386

Chui, A.C. W., Titman, S., Wei, K. C. J., 2010. Individualism and Momentum around the World. The Journal of Finance 65, 361-392.

Davis, A.K., Ge, W., Matsumoto, D., Zhang, J.L., 2014. The Effect of Manager-Specific Optimism on the Tone of Earnings Conference Calls. Review of Accounting Studies 20, 639-673.

Demers, E.A., Vega, C., 2014. Understanding The Role of Managerial Optimism and Uncertainty in the Price Formation Process: Evidence from the Textual Content of Earnings Announcements (SSRN Scholarly Paper No. ID 1152326). Social Science Research Network, Rochester, NY.

Dittmar, A.K., Duchin, R., 2015. Looking in the Rear View Mirror: The Effect of Managers' Professional Experience on Corporate Financial Policy (SSRN Scholarly Paper No. ID 2142465). Social Science Research Network, Rochester, NY.

Eun, C.S., Wang, L., Xiao, S.C., 2015. Culture and R2. Journal of Financial Economics 115, 283-303.

Feldman, R., Govindaraj, S., Livnat, J., Segal, B., 2010. Management's Tone Change, Post Earnings Announcement Drift and Accruals. Review of Accounting Studies 15, 915-953.

Franke, R.H., Hofstede, G., Bond, M.H., 1991. Cultural Roots of Economic Performance: A Research note. Strategic Management Journal 12, 165-173.

Foley, C. F., and W. R. Kerr. 2013. Ethnic Innovation and U.S. Multinational Firm Activity. Management Science 59 (7): 1529-1544.

Giuliano, P., A. Spilimbergo, and G. Tonon, 2013. Genetic distance, transportation costs, and trade. Journal of Economic Geography 14, 179-198.

Gluszek A., and J. F. Dovidio 2010. The way they speak: A social psychological perspective on the stigma of nonnative accents in communication. Personality and social psychology review 14(2): 214-237.

Gorodnichenko, Y., and G. Roland. 2010. Culture, Institutions and the Wealth of Nations. Working Paper. National Bureau of Economic Research. 
Gorodnichenko, Y., Roland, G., 2011. Which Dimensions of Culture Matter for Long-Run Growth? American Economic Review 101, 492-98.

Gorodnichenko, Y., Roland, G., 2012. Understanding the Individualism-Collectivism Cleavage and its Effects: Lessons from Cultural Psychology In Aoki, M., T. Kuran, and G. Roland. Institutions and Comparative Economic Development. Palgrave Macmillan.

Gow, I. D., S. N. Kaplan, D. F. Larcker, and A. A. Zakolyukina. 2015. CEO Personality and Firm Policies. Working Paper.

Graham, J. R., C. R. Harvey, J. Popadak, and S. Rajgopal. 2015. Corporate Culture: Evidence from the Field. Working Paper.

Guiso, L., Sapienza, P., Zingales, L., 2006. Does Culture Affect Economic Outcomes? The Journal of Economic Perspectives 20, 23-48.

Guiso, L., P. Sapienza, and L. Zingales. 2015. The value of corporate culture. Journal of Financial Economics 117 (1). NBER Conference on the Causes and Consequences of Corporate Culture: 6076.

Hallahan, M., F., Lee, Herzog, T., 1997. It's not just whether you win or lose it is also where you play the game: Cross cultural differences in the positivity bias. Journal of Cross Cultural Psychology, 28, 768778.

Heine S. J., 2008. Cultural psychology, W.W. Norton \& company.

Heine, S. J., 2010. Cultural Psychology, Handbook of Social Psychology, D. Fiske, D. Gilbert and G. Lindzey.

Heine, S.J., Lehman, D.R., Markus, H.R., Kitayama, S., 1999. Is There a Universal Need for Positive SelfRegard? Psychological Review 106, 766-794.

Henry, E., 2008. Are Investors Influenced by How Earnings Press Releases Are Written? Journal of Business Communication 45, 363-407.

Hofstede, G., 2001. Culture's Consequences: Comparing Values, Behaviors, Institutions, and Organizations across Nations. Thousand Oaks, CA: Sage Publications.

Hofstede, G., Neuijen, B., Ohayv, D.D., Sanders, G., 1990. Measuring Organizational Cultures: A Qualitative and Quantitative Study across Twenty Cases. Administrative Science Quarterly 35, 286316.

Hope, O.-K. 2003. Firm-level Disclosures and the Relative Roles of Culture and Legal Origin. Journal of International Financial Management \& Accounting 14 (3): 218-248.

Hope, O.-K., T. Kang, W. Thomas, and Y. K. Yoo. 2008. Culture and auditor choice: A test of the secrecy hypothesis. Journal of Accounting and Public Policy 27 (5): 357-373

Huang, X., Teoh, S.H., Zhang, Y., 2014. Tone Management. The Accounting Review 89, 1083-1113.

Kachelmeier, S.J., Shehata, M., 1997. Internal Auditing and Voluntary Cooperation in Firms: A CrossCultural Experiment. The Accounting Review 72, 407-431.

Kagitcibasi, C, 1997. Individualism and Collectivism. Handbook of Cross-Cultural Psychology 3, 1-49.

Karolyi, G.A., 2015. The Gravity of Culture for Finance (SSRN Scholarly Paper No. ID 2600702). Social Science Research Network, Rochester, NY. 
Kashima. E., and Y. Kashima. 1008. The Case of Cultural Dimensions and Personal Pronoun Use. Journal of Cross-Cultural Psychology 29(3): 461-486.

Kerr, W.R., 2008. Ethnic Scientific Communities and International Technology Diffusion. Review of Economics and Statistics 90, 518-537.

Kerr, W. R. 2010. Breakthrough inventions and migrating clusters of innovation. Journal of Urban Economics 67 (1). Special Issue: Cities and Entrepreneurship Sponsored by the Ewing Marion Kauffman Foundation (www.kauffman.org): 46-60.

Kimbrough, M.D., Wang, I.Y., 2014. Are Seemingly Self-Serving Attributions in Earnings Press Releases Plausible? Empirical Evidence. The Accounting Review 89, 635-667.

Kitayama, S., Markus, H.R., Matsumoto, H., Norasakkunkit, V., 1997. Individual and Collective Processes in the Construction of the Self: Self-Enhancement in the United States and Self-Criticism in Japan. Journal of Personality and Social Psychology 72, 1245-1267.

Kobayashi, C., and Brown, J. D. 2003. Self-esteem and self-enhancement in Japan and America. Journal of Cross-Cultural Psychology 34(5): 567-580.

La Porta, R., F. Lopez-de-Silanes, A. Shleifer, and R. Vishny. 1998. Law and finance. Journal of Political Economy 106: 1113-55.

Lee, J. A., 2016. Can Investors Detect Managers' Lack of Spontaneity? Adherence to Pre-determined Scripts during Earnings Conference Calls. The Accounting Review 91(1), 229-250.

Lewis, M. P., Gary F. S., and Charles D. F., 2009. Ethnologue: Languages of the World. Vol. 9. Dallas, TX: SIL International.

Li, F., 2010, Managers' self-serving attribution bias and corporate financial policies, Working paper, University of Michigan.

Li, F., Minnis, M., Nagar, V., and Rajan, M.V., 2014. Knowledge, Compensation, and Firm Value: An Empirical Analysis of Firm Communication. Journal of Accounting and Economics 58 (1):96-116.

Libby, R., Rennekamp, K., 2012. Self-Serving Attribution Bias, Overconfidence, and the Issuance of Management Forecasts. Journal of Accounting Research 50, 197-231.

Loughran, T., Mcdonald, B., 2011. When Is a Liability Not a Liability? Textual Analysis, Dictionaries, and 10-Ks. The Journal of Finance 66, 35-65.

Maddux, W. W., P. H. Kim, T. Okumura, and J. M. Brett. 2011. Cultural Differences in the Function and Meaning of Apologies. International Negotiation 16 (3): 405-425.

Malmendier, U., Tate, G., Yan, J., 2011. Overconfidence and Early-Life Experiences: The Effect of Managerial Traits on Corporate Financial Policies. The Journal of Finance 66, 1687-1733.

Markus, H.R., Kitayama, S., 1991. Culture and the Self: Implications for Cognition, Emotion, and Motivation. Psychological Review 98, 224-253.

Matsumoto, D., M. Pronk, and E. Roelofsen. 2011. What Makes Conference Calls Useful? The Information Content of Managers' Presentations and Analysts' Discussion Sessions. The Accounting Review 86 (4): $1383-1414$.

Morck, R., B. Yeung, and W. Yu, 2000. The Information Content of Stock Markets: Why Do Emerging Markets Have Synchronous Stock Price Movements? Journal of Financial Economics 58, 215-238. 
Na, J., and I. Choi. 2009. Culture and First-Person Pronouns. Personality and Social Psychology Bulletin 35(11): 1492-1499.

Okimoto, T. G., M. Wenzel, and K. Hedrick. 2013. Refusing to apologize can have psychological benefits (and we issue no mea culpa for this research finding). European Journal of Social Psychology 43 (1): $22-31$.

Pan, Y., Siegel, S., Wang, T.Y., 2015. Corporate Risk Culture. Working paper.

Price, S., J. Doran., D. Peterson, B. Bliss. 2012. Earnings conference calls and stock returns: The incremental informativeness of textual tone. Journal of Banking and Finance 36(4): 992- 1011.

Pevzner, M., Xie, F., Xin, X., 2015. When Firms Talk, Do Investors Listen? The Role of Trust in Stock Market Reactions to Corporate Earnings Announcements. Journal of Financial Economics 117, 190223.

Robalino, N., Robson, A.J., 2013. Genes, Culture, and Preferences. Biology Theory 8, 151-157.

Roussanov, N., Savor, P.G., 2012. Status, Marriage, and Managers' Attitudes to Risk. National Bureau of Economic Research Working Paper.

Schultz, J.J., Jr., Johnson, D.A., Morris, D., Dyrnes, S., 1993. An Investigation of the Reporting of Questionable Acts in an International Setting. Journal of Accounting Research 31, 75-103.

Shroff, N., Verdi, R.S., Yu, G., 2014. Information Environment and the Investment Decisions of Multinational Corporations. The Accounting Review 89, 759-790.

Sims, T., Tsai, J. L., Jiang, D., Wang, Y., Fung, H. H., and Zhang, X. 2015. Wanting to Maximize the Positive and Minimize the Negative: Implications for Mixed Affective Experience in American and Chinese Contexts. Journal of Personality and Social Psychology, Forthcoming.

Sugimoto, N. 1997. A Japan-U.S. Comparison of Apology Styles. Communication Research 24 (4): 349369.

Takagi, T. 1996. Americans don't apologize, Japanese apologize easily (in Japanese) Soshisya.

Taylor, S.E., Brown, J.D., 1988. Illusion and Well-Being: A Social Psychological Perspective on Mental Health. Psychological Bulletin 103, 193-210.

Triandis, H.C., 1995. Individualism \& Collectivism. New Directions in Social Psychology. Boulder, CO: Westview Press.

Uz, I. 2014. Individualism and First Person Pronoun Use in Written Texts Across Languages. Journal of Cross-Cultural Psychology 45(10): 1671-1678.

Van den Steen, E. 2010. On the origin of shared beliefs (and corporate culture). The RAND Journal of Economics 41 (4): 617-648.

Weber, Y., Shenkar, O., Raveh, A., 1996. National and Corporate Cultural Fit in Mergers/Acquisitions: An Exploratory Study. Management Science 42, 1215-1227.

Yeh, R.-S., Lawrence, J.J., 1995. Individualism and Confucian Dynamism: A Note on Hofstede's Cultural Root to Economic Growth. Journal of International Business Studies 26, 655-669.

Zuckerman, M., 1979. Attribution of Success and Failure Revisited, or: The Motivational Bias is Alive and Well in Attribution Theory. Journal of Personality 47, 245-287. 


\section{Appendix A: Ethnicity-name matching}

We map executive names into each ethnic group using the ethnicity-name matching technique developed by Kerr (2008). The matching process exploits the fact that people with particular first names and surnames are likely to be of a certain ethnicity. The underlying pool of ethnic names is based on the database of two marketing companies, Melissa Data Corporation, and List Services Direct, Inc., that developed the database for use in direct-mail advertisements. While other data vendors provide similar services, the advantage of the database provided by these companies is in their identification of Asian ethnicities, especially Chinese, Indian, Japanese, Korean, Russian/Slavic, and Vietnamese names (Kerr 2008).

We obtain the executives' first and last names from the conference call transcripts. The matching procedure utilizes all of the name assignments in the database and assigns a probability distribution of each name, giving first priority to last names. ${ }^{23}$ If a last name is assigned to all ethnic groups with a zero probability (or equal probabilities among multiple ethnicities), the algorithm then uses the first name to generate the match. The match rate following this procedure was at $96 \%$, which is comparable to the match rate found in other studies (Foley and Kerr 2013). ${ }^{24}$

The technique classifies each name into nine distinct ethnic groups: Anglo-Saxon, Chinese, European, Hispanic/Filipino, Indian, Japanese, Korean, Russian/Slavic, and Vietnamese. When applied to the conference call sample, no executives matched to the Vietnamese ethnic group. Thus, our analysis includes eight distinct groups. Table A1 shows the top five surnames of executives in each ethnic group.

Table A1 Top five surnames of managers speaking during conference calls, by ethnic group

\begin{tabular}{|c|c|c|c|c|c|c|c|c|}
\hline $\begin{array}{l}\text { Manager's } \\
\text { ethnic } \\
\text { group }\end{array}$ & Chinese & $\begin{array}{l}\text { Anglo- } \\
\text { Saxon }\end{array}$ & European & $\begin{array}{l}\text { Indian/ } \\
\text { South Asian }\end{array}$ & Hispanic/Filipino & Japanese & Korean & Russian/Slavic \\
\hline Top 1 & Chen & Smith & Schwartz & Shah & Garcia & Tanaka & Kim & Kaminski \\
\hline 2 & Wang & Johnson & Schmidt & Patel & Lopez & Suzuki & Park & Brodsky \\
\hline 3 & Wong & Miller & Weiss & Singh & Sanchez & Kato & Choi & Lasky \\
\hline 4 & Chan & Brown & Meyer & Kumar & Fernandez & Santo & Cho & Khaykin \\
\hline Top 5 & $\mathrm{Li}$ & Jones & Wagner & Gupta & Perez & Takahashi & Jung & Radinsky \\
\hline
\end{tabular}

${ }^{23}$ See Kerr (2008) for more details on the matching process.

24 The list obtained from Kerr (2010) excludes Jewish names (the most prominent examples being Cohen, Katz, etc.), due to difficulties in classifying the individuals. For this reason, we exclude firms domiciled in Israel from our conference call sample. 


\section{Appendix B: Variable definitions}

Panel A Definitions of the variables

\begin{tabular}{|c|c|c|}
\hline Category & Variable name & Empirical measure \& data source \\
\hline \multirow[t]{7}{*}{$\begin{array}{l}\text { Dependent } \\
\text { Variables }\end{array}$} & Tone_Q\&A(MD) & $\begin{array}{l}\text { The number of times the manager uses "positive" words minus } \\
\text { the number of times the manager uses "negative" words scaled } \\
\text { by the total number of "positive" plus "negative" words during } \\
\text { the Q\&A (MD). }\end{array}$ \\
\hline & Self-Reference_Q\&A (MD) & $\begin{array}{l}\text { The number of times the manager uses singular first-person } \\
\text { pronouns ("I", "me", "mine", "my", "myself") during the Q\&A } \\
\text { (MD) scaled by the total number of words. }\end{array}$ \\
\hline & Apologies_Q\&A(MD) & $\begin{array}{l}\text { The number of times the manager apologizes ("apolog*", } \\
\text { "sorry")) during the Q\&A (MD) scaled by the total number of } \\
\text { words. }\end{array}$ \\
\hline & Standard deviation in tone & $\begin{array}{l}\text { The standard deviation of Tone of all executives in a firm } \\
\text { computed annually using transcripts in each firm-year. }\end{array}$ \\
\hline & $\begin{array}{l}\text { Standard deviation in self- } \\
\text { reference }\end{array}$ & $\begin{array}{l}\text { The standard deviation of Self-reference of all executives in a } \\
\text { firm computed annually using transcripts in each firm-year. }\end{array}$ \\
\hline & Standard deviation in apologies & $\begin{array}{l}\text { The standard deviation of Apologies of all executives in a firm } \\
\text { computed annually using transcripts in each firm-year. }\end{array}$ \\
\hline & Abnormal returns & Sum of the three-day market-model-adjusted returns. \\
\hline \multirow{4}{*}{$\begin{array}{l}\text { Manager } \\
\text { (Analysts) } \\
\text { characteristics }\end{array}$} & Gender & Indicator equal to 1 if the manager is female, 0 otherwise. \\
\hline & Age & Age of the manager. \\
\hline & Degree & $\begin{array}{l}\text { Indicator equal to } 1 \text { if the manager obtained a graduate degree, } \\
0 \text { otherwise. }\end{array}$ \\
\hline & Same ethnicity & $\begin{array}{l}\text { Indicator equal to } 1 \text { if the forecast is issued by an analyst with } \\
\text { the ethnic background of the firm's region, } 0 \text { otherwise. }\end{array}$ \\
\hline
\end{tabular}

Firm

characteristics

Words
Participants
Size
$Q$
Leverage
ROA

ESUR

Log analysts

D_loss

Year_end

Ret_fye

Return volatility
The number of words in the Q\&A section.

Number of non-corporate participants in the call.

Log market value of equity measured in U.S. dollars.

Log market value of assets over the book value of assets.

Total debt over the book value of assets.

Net income before extraordinary items over the total value of assets.

Difference between the actual annual EPS minus the most recent mean analyst forecast, if available, or a seasonal random walk model otherwise scaled by price. We use decile ranks scaled to range between zero and one.

Log of the number of analysts covering the firm. Indicator variable equal to 1 for firms reporting negative earnings.

Indicator variable equal to 1 for conference calls corresponding to the fourth fiscal quarter, and 0 otherwise. Prior fiscal year return.

Yearly standard deviation of daily abnormal returns in the year prior to the conference call. 
Earnings volatility

Replag
5 year standard deviation of net income (minimum 3 years of data required) scaled by total assets. The five-year window ends with the fiscal year of the conference call.

Time from the firm's fiscal year end to the conference call date.

\section{Appendix B: Variable definitions (Continued)}

\begin{tabular}{|c|c|c|}
\hline Category & Variable name & Empirical measure \& data source \\
\hline \multirow[t]{10}{*}{$\begin{array}{l}\text { Country } \\
\text { characteristics }\end{array}$} & Individualism & $\begin{array}{l}\text { Average of Hofstede's country-level individualism index by } \\
\text { ethnicity. The measure is retrieved from } \\
\text { http://geert-hofstede.com/countries.html. }\end{array}$ \\
\hline & Language distance & $\begin{array}{l}\text { Distance between English and the main language of each country } \\
\text { studied, based on a 5-point scale classification system (see Lewis } \\
\text { (2009) for details at http://www.ethnologue.com/web.asp). }\end{array}$ \\
\hline & Lack of trust & $\begin{array}{l}\text { Skepticism index from the World Values Survey. The measure is } \\
\text { retrieved from http://www.worldvaluessurvey.org/ }\end{array}$ \\
\hline & Uncertainty avoidance & $\begin{array}{l}\text { Hofstede's country-level Uncertainty Avoidance Index retrieved } \\
\text { from http://geert-hofstede.com/countries.html. }\end{array}$ \\
\hline & Market cap & $\begin{array}{l}\text { Equity market capitalization of the country's global Datastream } \\
\text { Index. }\end{array}$ \\
\hline & Market return & Annual change in the Datastream global market index. \\
\hline & Synchronicity & $\begin{array}{l}\text { National average firm-level measure of synchronicity following } \\
\text { Morck et al. (2000). Synchronicity }=\log \left(\mathrm{R}^{2} /\left(1-\mathrm{R}^{2}\right) \text { where } \mathrm{R}^{2} \text { is }\right. \\
\text { obtained from the yearly market model regression of daily returns. }\end{array}$ \\
\hline & Zero returns & Yearly country average firm-level percentage of daily zero returns. \\
\hline & Accrual & $\begin{array}{l}\text { Country's average accruals. Accruals is defined as change in (current } \\
\text { assets-change in current liabilities -change in cash + change in short } \\
\text { term debt - depreciation)/ average total assets. }\end{array}$ \\
\hline & Law & Rule of law as per La Porta et al. (1998) \\
\hline
\end{tabular}


Table 1 Sample selection

\begin{tabular}{lrr}
\hline & $\begin{array}{c}\text { \# of conference } \\
\text { calls } \\
\text { (i.e., firm- } \\
\text { quarters) }\end{array}$ & $\begin{array}{c}\text { \# of individuals per } \\
\text { calls (i.e., manager- } \\
\text { quarter) }\end{array}$ \\
\hline Number of conference call transcripts 2002-2012 & 332,038 & $1,008,503$ \\
Less: Analyst calls, etc. & 110,135 & 249,216 \\
Less: Missing identifiers, Years & 142,387 & 515,762 \\
\hline & 79,516 & 243,525 \\
Less: Incomplete financials, returns & 15,523 & 36,630 \\
Less: Missing country's ethnicity (Israel) & 719 & 1,924 \\
Less: Countries with fewer than 30 observations & 73 & 2404,731 \\
\hline Less: Missing Managers Information (i.e. ethnicity, linguistic & 63,201 & $\mathbf{7 4 , 8 7 1}$ \\
measures) and short conference calls & 5,432 & 73 \\
Less: Translated calls & 29 & $\mathbf{1 2 9 , 7 8 7}$ \\
\hline Total number of observations & $\mathbf{5 7 , 7 4 0}$ & \\
\hline \hline
\end{tabular}




\section{Table 2 Descriptive statistic of manager's cultural background based on ethnicity}

Panel A Distribution of the ethnic group of managers

\begin{tabular}{|c|c|c|c|c|c|c|c|}
\hline \multirow{2}{*}{$\begin{array}{l}\text { Manager's } \\
\text { cultural background }\end{array}$} & \multirow[t]{2}{*}{ Var } & \multirow{2}{*}{$\begin{array}{l}\text { Individualism } \\
\text { measure }(\times 100)\end{array}$} & \multirow{2}{*}{$\begin{array}{r}\text { \# of } \\
\text { managers }\end{array}$} & \multirow{2}{*}{$\begin{array}{c}\% \text { of managers with ethnic } \\
\text { cultural background identical to } \\
\text { the firm's region }\end{array}$} & \multicolumn{3}{|c|}{ Mean disclosure attributes } \\
\hline & & & & & Tone & Self-reference & Apologies \\
\hline Anglo-Saxon & ENG & 89.51 & 16,831 & $77 \%$ & 0.159 & 1.552 & 0.021 \\
\hline European & EUR & 65.76 & 4,156 & $48 \%$ & 0.088 & 1.500 & 0.027 \\
\hline Japanese & JAP & 46.00 & 175 & $44 \%$ & 0.076 & 1.381 & 0.041 \\
\hline Indian/South Asian & IND & 42.16 & 754 & $67 \%$ & 0.108 & 1.493 & 0.025 \\
\hline Russian/Slavic & RUS & 39.00 & 428 & $53 \%$ & 0.089 & 1.328 & 0.027 \\
\hline Hispanic & HIS & 33.16 & 1,523 & $69 \%$ & 0.091 & 1.322 & 0.033 \\
\hline Chinese & $\mathrm{CHN}$ & 20.41 & 899 & $64 \%$ & 0.087 & 1.291 & 0.037 \\
\hline South Korean & KOR & 18.00 & 135 & $77 \%$ & -0.003 & 1.518 & 0.036 \\
\hline Total & & & 24,901 & $74 \%$ & 0.139 & 1.519 & 0.023 \\
\hline
\end{tabular}

Panel B Distribution of the ethnic group of managers, by firm's region

\begin{tabular}{|c|c|c|c|c|c|c|c|c|c|c|}
\hline Firm's region $\backslash$ Manager's ethnic group & $\begin{array}{c}\text { \# of m- } \\
\text { quarters }\end{array}$ & ENG & EUR & JAP & IND & RUS & HIS & $\mathrm{CHN}$ & KOR & Total \\
\hline U.S., UK, Australia, New Zealand, Canada & 111,071 & $\mathbf{7 8 \%}$ & $13 \%$ & $0 \%$ & $2 \%$ & $1 \%$ & $3 \%$ & $3 \%$ & $0 \%$ & $100 \%$ \\
\hline Europe & 13,682 & $36 \%$ & $48 \%$ & $0 \%$ & $1 \%$ & $2 \%$ & $11 \%$ & $1 \%$ & $0 \%$ & $100 \%$ \\
\hline Japan & 391 & $37 \%$ & $6 \%$ & $44 \%$ & $2 \%$ & $2 \%$ & $3 \%$ & $4 \%$ & $2 \%$ & $100 \%$ \\
\hline India, Bangladesh, and Pakistan & 932 & $22 \%$ & $4 \%$ & $0 \%$ & $67 \%$ & $2 \%$ & $3 \%$ & $1 \%$ & $0 \%$ & $100 \%$ \\
\hline Russia/Slavic & 288 & $44 \%$ & $2 \%$ & $0 \%$ & $0 \%$ & $53 \%$ & $0 \%$ & $0 \%$ & $0 \%$ & $100 \%$ \\
\hline Hispanic Nations & 2,409 & $18 \%$ & $11 \%$ & $0 \%$ & $0 \%$ & $1 \%$ & $69 \%$ & $0 \%$ & $0 \%$ & $100 \%$ \\
\hline China, Hong Kong, Singapore, and Taiwan & 852 & $21 \%$ & $3 \%$ & $1 \%$ & $6 \%$ & $0 \%$ & $4 \%$ & $64 \%$ & $2 \%$ & $100 \%$ \\
\hline South Korea & 162 & $3 \%$ & $0 \%$ & $0 \%$ & $0 \%$ & $4 \%$ & $1 \%$ & $14 \%$ & $77 \%$ & $100 \%$ \\
\hline
\end{tabular}


Table 2 (Continued)

Panel C Distribution of the ethnic group of managers, by year

\begin{tabular}{|c|c|c|c|c|c|c|c|c|c|}
\hline $\begin{array}{l}\text { Call- year } \\
\backslash \text { Manager's ethnic group }\end{array}$ & ENG & EUR & JAP & IND & RUS & HIS & $\mathrm{CHN}$ & KOR & $\begin{array}{r}\text { Total } \\
\text { \# of } \\
\text { managers }\end{array}$ \\
\hline 2002 & $81.1 \%$ & $14.1 \%$ & $0.0 \%$ & $0.0 \%$ & $0.0 \%$ & $3.3 \%$ & $1.5 \%$ & $0.0 \%$ & 2,534 \\
\hline 2003 & $77.5 \%$ & $13.3 \%$ & $0.5 \%$ & $2.5 \%$ & $0.0 \%$ & $4.4 \%$ & $1.6 \%$ & $0.2 \%$ & 5,837 \\
\hline 2004 & $73.5 \%$ & $15.3 \%$ & $0.4 \%$ & $2.7 \%$ & $1.7 \%$ & $4.8 \%$ & $1.4 \%$ & $0.3 \%$ & 8,644 \\
\hline 2005 & $72.9 \%$ & $16.2 \%$ & $0.5 \%$ & $2.1 \%$ & $1.8 \%$ & $4.5 \%$ & $1.8 \%$ & $0.2 \%$ & 8,444 \\
\hline 2006 & $72.2 \%$ & $16.8 \%$ & $0.6 \%$ & $2.1 \%$ & $1.5 \%$ & $4.4 \%$ & $2.1 \%$ & $0.3 \%$ & 9,586 \\
\hline 2007 & $70.5 \%$ & $17.2 \%$ & $1.0 \%$ & $2.1 \%$ & $1.5 \%$ & $4.4 \%$ & $3.0 \%$ & $0.3 \%$ & 10,914 \\
\hline 2008 & $70.4 \%$ & $18.1 \%$ & $0.7 \%$ & $2.0 \%$ & $1.5 \%$ & $4.4 \%$ & $2.8 \%$ & $0.2 \%$ & 12,813 \\
\hline 2009 & $69.1 \%$ & $17.2 \%$ & $0.6 \%$ & $2.3 \%$ & $1.4 \%$ & $5.1 \%$ & $4.0 \%$ & $0.2 \%$ & 13,547 \\
\hline 2010 & $69.3 \%$ & $16.7 \%$ & $0.6 \%$ & $2.4 \%$ & $1.7 \%$ & $5.4 \%$ & $3.6 \%$ & $0.4 \%$ & 15,989 \\
\hline 2011 & $70.8 \%$ & $15.8 \%$ & $0.5 \%$ & $3.2 \%$ & $1.5 \%$ & $5.1 \%$ & $2.6 \%$ & $0.4 \%$ & 19,787 \\
\hline 2012 & $68.9 \%$ & $15.3 \%$ & $0.4 \%$ & $4.0 \%$ & $1.7 \%$ & $6.2 \%$ & $3.1 \%$ & $0.4 \%$ & 21,692 \\
\hline
\end{tabular}

Notes: This table describes our sample. Unless otherwise noted, the unit of observation is a manager-conference call pair. Managers are assigned to one of eight ethnicities (a ninth ethnicity, Vietnamese, had no match in our sample) according to Kerr (2008) and based on a database from Melissa Data Corp. and List Services Direct Inc. See Appendix A and Kerr (2008) for more details. Panel A reports statistical means for our main variables of interest. We obtain the individualism measure from Hofstede (2001). Since Hofstede's data is at the country level, we convert individualism to an ethnicity-level measure using the average of the individualism index of all countries that belong to the ethnic group. We weight the measure by the number of firms in each country (using our conference call sample). See Appendix B for detailed definitions of disclosure attributes Tone, Self-Reference, and Apologies. In Panel B, the countries included in each firm's regions is as the following: Europe includes Austria, Belgium, Denmark, Finland, France, Germany, Italy, Luxembourg, Netherlands, Norway, Poland, Sweden, and Switzerland. Hispanic Nations include Argentina, Belize, Brazil, Chile, Columbia, Costa Rica, Cuba, Dominican Republic, Ecuador, El Salvador, Guatemala, Honduras, Mexico, Nicaragua, Panama, Paraguay, Peru, Philippines, Portugal, Spain, Uruguay, and Venezuela. Russia include Russia and all Soviet Union Countries. Panel $\mathrm{C}$ reports the sample breakdown by year and ethnicity. 


\section{Table 3 Descriptive statistics}

Panel A: Descriptive statistics of disclosure attributes

\begin{tabular}{lcrrrrrrr}
\hline Variable & $\mathrm{N}$ & \multicolumn{1}{c}{ Mean } & ST Dev & \multicolumn{1}{c}{ P10 } & \multicolumn{1}{c}{ P25 } & P50 & P75 & P90 \\
\hline Tone_Q\&A & 129,787 & 0.14 & 0.52 & -0.60 & -0.14 & 0.20 & 0.50 & 0.80 \\
Self-reference_Q\&A & 129,787 & 1.52 & 0.96 & 0.35 & 0.86 & 1.42 & 2.05 & 2.76 \\
Apologies_Q\&A & 129,787 & 0.02 & 0.07 & 0.00 & 0.00 & 0.00 & 0.00 & 0.07 \\
Tone_MD & 105,311 & 0.26 & 0.42 & -0.33 & 0.00 & 0.31 & 0.57 & 0.75 \\
Self-reference_MD & 105,311 & 0.66 & 0.61 & 0.15 & 0.29 & 0.51 & 0.85 & 1.32 \\
Apologies_MD & 105,311 & 0.004 & 0.02 & 0.00 & 0.00 & 0.00 & 0.00 & 0.00
\end{tabular}

Panel B: Descriptive statistics of the capital market variables and other call characteristics

\begin{tabular}{|c|c|c|c|c|c|c|c|c|}
\hline & $\mathrm{N}$ & Mean & ST Dev & P10 & $\mathrm{P} 25$ & P50 & P75 & P90 \\
\hline \multicolumn{9}{|c|}{ Capital market reaction } \\
\hline Abn. Ret. Q\&A,t \% & 15,533 & -0.02 & 1.71 & -1.38 & -0.48 & 0.00 & 0.46 & 1.33 \\
\hline Abn. Ret. Pres.,t \% & 15,533 & 0.00 & 1.64 & -1.24 & -0.43 & 0.00 & 0.42 & 1.24 \\
\hline Individualism $_{m}$ & 129,787 & 0.78 & 0.20 & 0.42 & 0.66 & 0.90 & 0.90 & 0.90 \\
\hline Gender $_{\mathrm{m}}$ & 78,506 & 0.06 & 0.24 & 0.00 & 0.00 & 0.00 & 0.00 & 0.00 \\
\hline $\operatorname{Age}_{\mathrm{m}, \mathrm{t}}$ & 75,886 & 52.77 & 8.00 & 42.41 & 47.35 & 52.62 & 58.13 & 62.83 \\
\hline Degree $_{\mathrm{m}}$ & 27,583 & 0.10 & 0.29 & 0.00 & 0.00 & 0.00 & 0.00 & 0.00 \\
\hline Plain English $\mathrm{m}_{\mathrm{m}, \mathrm{t}}$ & 129,787 & 0.09 & 1.80 & -1.80 & -1.00 & -0.10 & 0.93 & 2.10 \\
\hline Grammar Errors $_{\mathrm{m}, \mathrm{t}}$ & 129,787 & 0.00 & 1.00 & -0.82 & -0.58 & -0.18 & 0.27 & 0.90 \\
\hline Words $_{\mathrm{i}, \mathrm{t}}$ & 129,787 & $1,041.1$ & $1,043.9$ & 112.00 & 283.00 & 700.00 & $1,465.0$ & $2,450.0$ \\
\hline Participants $_{\mathrm{i}, \mathrm{t}}$ & 129,787 & 1.86 & 0.53 & 1.10 & 1.61 & 1.95 & 2.20 & 2.48 \\
\hline Size $_{i, t}$ & 129,787 & 13.45 & 1.93 & 11.04 & 12.25 & 13.41 & 14.64 & 16.05 \\
\hline $\mathrm{Q}_{\mathrm{i}, \mathrm{t}}$ & 129,787 & 1.79 & 1.33 & 0.93 & 1.05 & 1.32 & 1.97 & 3.22 \\
\hline Leverage $_{\mathrm{i}, \mathrm{t}}$ & 129,787 & 0.23 & 0.38 & 0.00 & 0.04 & 0.18 & 0.35 & 0.53 \\
\hline $\mathrm{ROA}_{\mathrm{i}, \mathrm{t}}$ & 129,787 & -0.01 & 0.19 & -0.15 & 0.00 & 0.03 & 0.07 & 0.12 \\
\hline ESUR $_{\mathrm{i}, \mathrm{t}}$ & 129,787 & 0.49 & 0.32 & 0.00 & 0.22 & 0.56 & 0.78 & 1.00 \\
\hline $\log$ analysts $\mathrm{s}_{\mathrm{i}, \mathrm{t}}$ & 129,787 & 1.40 & 0.95 & 0.00 & 0.69 & 1.61 & 2.08 & 2.56 \\
\hline D_loss $\mathrm{s}_{\mathrm{i}, \mathrm{t}}$ & 129,787 & 0.34 & 0.47 & 0.00 & 0.00 & 0.00 & 1.00 & 1.00 \\
\hline Year_end ${ }_{i, t}$ & 129,787 & 0.25 & 0.43 & 0.00 & 0.00 & 0.00 & 1.00 & 1.00 \\
\hline Ret_fye $e_{i, t}$ & 129,787 & 0.19 & 0.69 & -0.48 & -0.19 & 0.09 & 0.38 & 0.84 \\
\hline Return volatility $\mathrm{y}_{\mathrm{i}, \mathrm{t}}$ & 57,740 & 0.03 & 0.02 & 0.01 & 0.02 & 0.03 & 0.04 & 0.05 \\
\hline Earnings volatility ${ }_{\mathrm{i}, \mathrm{t}}$ & 57,740 & 0.08 & 0.15 & 0.01 & 0.01 & 0.03 & 0.08 & 0.20 \\
\hline $\operatorname{Replag}_{\mathrm{i}, \mathrm{t}}$ & 57,740 & 14.33 & 101.11 & 15.50 & 25.00 & 33.00 & 41.00 & 59.00 \\
\hline Lack of trust $t_{c(m)}$ & 129,787 & 0.39 & 0.05 & 0.36 & 0.37 & 0.37 & 0.38 & 0.42 \\
\hline Uncertainty $_{c(m), t}$ & 129,787 & 51.18 & 11.28 & 46.27 & 46.27 & 46.27 & 46.27 & 63.18 \\
\hline Market cap ${ }_{c, t}$ & 129,787 & 9.28 & 6.09 & 0.52 & 1.42 & 11.55 & 14.40 & 16.34 \\
\hline Market return $_{\mathrm{c}, \mathrm{t}}$ & 129,787 & 0.08 & 0.20 & -0.28 & 0.01 & 0.14 & 0.17 & 0.28 \\
\hline Synchronicity $\mathrm{c}_{\mathrm{c}, \mathrm{t}}$ & 129,787 & 0.10 & 0.04 & 0.05 & 0.07 & 0.09 & 0.13 & 0.17 \\
\hline Zero returns $_{\mathrm{c}, \mathrm{t}}$ & 129,787 & 0.39 & 0.06 & 0.34 & 0.35 & 0.37 & 0.40 & 0.48 \\
\hline $\mathrm{Law}_{\mathrm{c}}$ & 129,787 & 9.69 & 1.23 & 9.23 & 10.00 & 10.00 & 10.00 & 10.00 \\
\hline
\end{tabular}

Notes: This table reports descriptive statistics for the variables in our regression analyses. See Appendix B for detailed variable definitions. 
Table 4 Effect of manager's ethnic background on disclosure attributes

Panel A Cross-country sample

\begin{tabular}{|c|c|c|c|}
\hline \multirow{2}{*}{ Variables } & \multirow{2}{*}{$\begin{array}{c}\text { (1) Tone_Q\&A } \mathrm{i}, \mathrm{m}, \mathrm{t} \\
\text { Coeff } \\
(t \text {-stat })\end{array}$} & \multirow{2}{*}{$\begin{array}{c}\text { (2) Self-reference_Q\&A } \\
\text { imt } \\
\text { Coeff } \\
(t \text {-stat })\end{array}$} & \multirow{2}{*}{$\begin{array}{c}\text { (3) Apologies_Q\& } \mathrm{A}_{\mathrm{i}, \mathrm{m}, \mathrm{t}} \\
\text { Coeff } \\
(t \text {-stat })\end{array}$} \\
\hline & & & \\
\hline \multicolumn{4}{|c|}{ Manager-call characteristics } \\
\hline Individualism $_{\mathrm{m}}$ & $\begin{array}{c}0.091 * * * \\
(4.507)\end{array}$ & $\begin{array}{c}0.174 * * * \\
(4.470)\end{array}$ & $\begin{array}{c}-0.015 * * * \\
(-6.203)\end{array}$ \\
\hline $\mathrm{CEO}_{\mathrm{m}}$ & $\begin{array}{l}0.169 * * * \\
(34.580)\end{array}$ & $\begin{array}{c}0.208 * * * \\
(17.421)\end{array}$ & $\begin{array}{c}-0.006 * * * \\
(-12.355)\end{array}$ \\
\hline Gender $_{\mathrm{m}}^{\dagger}$ & $\begin{array}{c}-0.051 * * * \\
(-2.836)\end{array}$ & $\begin{array}{c}-0.009 \\
(-0.237)\end{array}$ & $\begin{array}{c}0.006 * * * \\
(2.941)\end{array}$ \\
\hline Age $_{m, t^{\dagger}}$ & $\begin{array}{c}-0.001 * * * \\
(-4.142)\end{array}$ & $\begin{array}{c}0.005 * * * \\
(4.730)\end{array}$ & $\begin{array}{c}-0.000 * * * \\
(-2.782)\end{array}$ \\
\hline Degree $_{\mathrm{m}}^{\dagger}$ & $\begin{array}{c}-0.019 \\
(-0.975)\end{array}$ & $\begin{array}{c}-0.032 \\
(-0.683)\end{array}$ & $\begin{array}{c}0.000 \\
(0.000)\end{array}$ \\
\hline Plain English ${ }_{i, m, t}$ & $\begin{array}{c}0.023 * * * \\
(6.886)\end{array}$ & $\begin{array}{l}-0.132 * * * \\
(-15.362)\end{array}$ & $\begin{array}{c}-0.003 * * * \\
(-11.069)\end{array}$ \\
\hline Grammar error $_{\mathrm{im}, \mathrm{t}}$ & $\begin{array}{c}-0.041 * * * \\
(-3.876)\end{array}$ & $\begin{array}{c}0.092 * * * \\
(3.031)\end{array}$ & $\begin{array}{c}0.003 * * \\
(2.574)\end{array}$ \\
\hline \multicolumn{4}{|l|}{ Firm call characteristics } \\
\hline $\log _{W^{\prime}}$ ords $_{i, t}$ & $\begin{array}{c}0.007 \\
(1.097)\end{array}$ & $\begin{array}{c}0.050 * * * \\
(4.377)\end{array}$ & $\begin{array}{c}-0.003 * * * \\
(-4.032)\end{array}$ \\
\hline Log Participants $_{\mathrm{i}, \mathrm{t}}$ & $\begin{array}{c}0.008 \\
(1.148)\end{array}$ & $\begin{array}{c}0.008 \\
(0.518)\end{array}$ & $\begin{array}{c}0.005^{* * * *} \\
(3.627)\end{array}$ \\
\hline $\operatorname{Size}_{i, t}$ & $\begin{array}{c}-0.008 * * * \\
(-3.531)\end{array}$ & $\begin{array}{c}0.010 * * \\
(2.342)\end{array}$ & $\begin{array}{c}-0.000 \\
(-0.040)\end{array}$ \\
\hline$Q_{i, t}$ & $\begin{array}{c}0.001 \\
(0.555)\end{array}$ & $\begin{array}{c}-0.000 \\
(-0.026)\end{array}$ & $\begin{array}{c}0.000 \\
(0.641)\end{array}$ \\
\hline Leverage $_{\mathrm{i}, \mathrm{t}}$ & $\begin{array}{c}-0.009 \\
(-1.453)\end{array}$ & $\begin{array}{c}-0.003 \\
(-0.351)\end{array}$ & $\begin{array}{c}0.001 \\
(1.168)\end{array}$ \\
\hline $\mathrm{ROA}_{\mathrm{i}, \mathrm{t}}$ & $\begin{array}{c}0.008 \\
(0.429)\end{array}$ & $\begin{array}{l}-0.046^{*} \\
(-1.821)\end{array}$ & $\begin{array}{c}0.001 \\
(0.425)\end{array}$ \\
\hline $\mathrm{ESUR}_{\mathrm{i}, \mathrm{t}}$ & $\begin{array}{c}0.050 * * * \\
(9.180)\end{array}$ & $\begin{array}{c}-0.002 \\
(-0.169)\end{array}$ & $\begin{array}{c}-0.001 \\
(-0.924)\end{array}$ \\
\hline Log analysts $_{\mathrm{i}, \mathrm{t}}$ & $\begin{array}{c}0.003 \\
(0.689)\end{array}$ & $\begin{array}{c}-0.005 \\
(-0.637)\end{array}$ & $\begin{array}{c}-0.000 \\
(-0.658)\end{array}$ \\
\hline D_loss $s_{i, t}$ & $\begin{array}{c}-0.028 * * * \\
(-4.631)\end{array}$ & $\begin{array}{c}-0.009 \\
(-0.766)\end{array}$ & $\begin{array}{c}-0.000 \\
(-0.468)\end{array}$ \\
\hline Year_end ${ }_{i, t}$ & $\begin{array}{c}-0.001 \\
(-0.128)\end{array}$ & $\begin{array}{l}-0.000 \\
(-0.087)\end{array}$ & $\begin{array}{c}0.002 * * * \\
(2.827)\end{array}$ \\
\hline Ret_fye $e_{i, t}$ & $\begin{array}{c}0.010 * * * \\
(3.561)\end{array}$ & $\begin{array}{c}-0.032 * * * \\
(-5.217)\end{array}$ & $\begin{array}{c}-0.000 \\
(-0.881)\end{array}$ \\
\hline Country characteristics & & & \\
\hline Lack of trust $t_{c(m), t}$ & $\begin{array}{c}0.331 * * * \\
(2.624)\end{array}$ & $\begin{array}{c}-0.235 \\
(-0.879)\end{array}$ & $\begin{array}{c}-0.001 \\
(-0.024)\end{array}$ \\
\hline Uncertainty avoidance $_{c(m)}$ & $\begin{array}{l}-0.001 * \\
(-1.768)\end{array}$ & $\begin{array}{c}0.001 \\
(0.686)\end{array}$ & $\begin{array}{l}-0.000 \\
(-0.048)\end{array}$ \\
\hline Market cap $\mathrm{p}_{\mathrm{c}(\mathrm{i}), \mathrm{t}}$ & $\begin{array}{c}0.007 * * * \\
(7.959)\end{array}$ & $\begin{array}{c}-0.002 \\
(-1.258)\end{array}$ & $\begin{array}{c}-0.001 * * * \\
(-4.629)\end{array}$ \\
\hline Market return $_{\mathrm{c}(\mathrm{i}), \mathrm{t}}$ & $-0.061 *$ & -0.002 & $0.003 * *$ \\
\hline
\end{tabular}




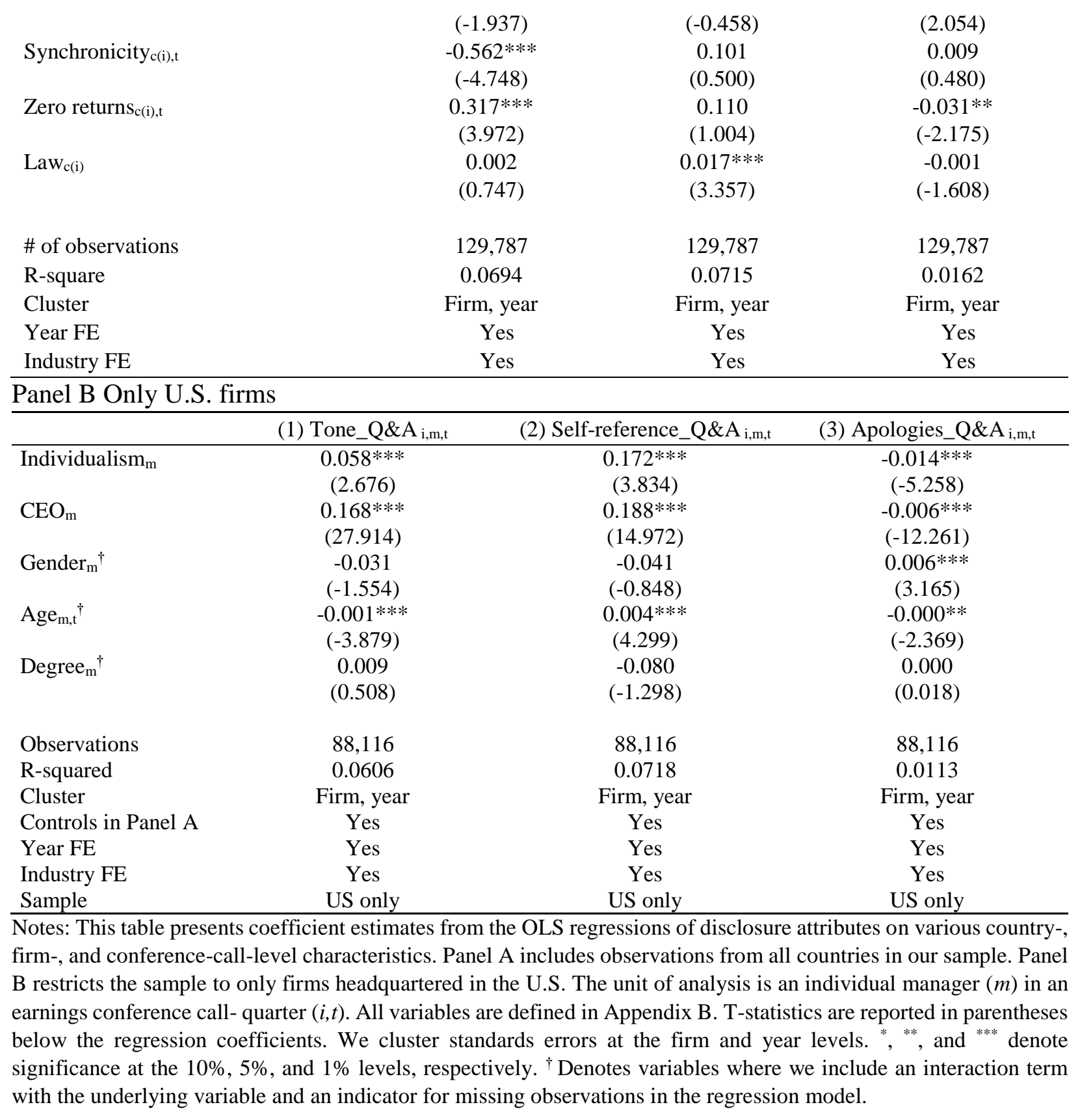


Table 5 The effect of manager's ethnic background for managers with cross cultural experience

Panel A: Cross-country sample

\begin{tabular}{|c|c|c|c|c|c|c|}
\hline \multirow{3}{*}{ Variables } & \multicolumn{2}{|c|}{ (1) Tone_Q\&A $\mathrm{A}_{\mathrm{i}, \mathrm{m}, \mathrm{t}}$} & \multicolumn{2}{|c|}{ (2) Self-reference_Q\&A $A_{i, m}$, } & \multicolumn{2}{|c|}{ (3) Apologies_Q\&A $\mathrm{i}_{i, \mathrm{~m}, \mathrm{t}}$} \\
\hline & Local & $\begin{array}{c}\text { Cross } \\
\text { cultural } \\
\text { experience }\end{array}$ & Local & $\begin{array}{c}\text { Cross cultura } \\
\text { experience }\end{array}$ & Local & $\begin{array}{c}\text { Cross } \\
\text { cultural } \\
\text { experience }\end{array}$ \\
\hline & $\begin{array}{c}\text { Coeff } \\
(t \text {-stat })\end{array}$ & $\begin{array}{c}\text { Coeff } \\
(t \text {-stat })\end{array}$ & $\begin{array}{c}\text { Coeff } \\
(t \text {-stat })\end{array}$ & $\begin{array}{c}\text { Coeff } \\
(t \text {-stat })\end{array}$ & $\begin{array}{c}\text { Coeff } \\
(t \text {-stat })\end{array}$ & $\begin{array}{c}\text { Coeff } \\
(t \text {-stat })\end{array}$ \\
\hline \multicolumn{7}{|c|}{ Manager-call characteristics } \\
\hline \multirow[t]{2}{*}{ Individualism $_{\mathrm{m}}$} & $\begin{array}{l}0.273 * * * \\
(3.906)\end{array}$ & $\begin{array}{l}0.092 * * \\
(2.242)\end{array}$ & $\begin{array}{l}0.372 * * * \\
(2.744)\end{array}$ & $\begin{array}{l}0.162 * * * \\
(2.819)\end{array}$ & $\begin{array}{l}-0.031 * * \\
(-2.021)\end{array}$ & $\begin{array}{c}-0.017 * * * \\
(-3.173)\end{array}$ \\
\hline & \multicolumn{2}{|c|}{$\begin{array}{c}\mathrm{F} \text { test } \\
\mathrm{P} \text { value }=0.0224\end{array}$} & \multicolumn{2}{|c|}{$\begin{array}{c}\mathrm{F} \text { test } \\
\mathrm{P} \text { value }=0.2669\end{array}$} & \multicolumn{2}{|c|}{$\begin{array}{c}\mathrm{F} \text { test } \\
\mathrm{P} \text { value }=0.2499\end{array}$} \\
\hline $\mathrm{CEO}_{\mathrm{m}}$ & $\begin{array}{c}0.164 * * * \\
(27.400)\end{array}$ & $\begin{array}{c}0.177 * * * \\
(24.168)\end{array}$ & $\begin{array}{c}0.206 * * * \\
(15.307)\end{array}$ & $\begin{array}{c}0.213 * * * \\
(11.388)\end{array}$ & $\begin{array}{c}-0.006^{* * * *} \\
(-7.229)\end{array}$ & $\begin{array}{c}-0.008 * * * \\
(-6.700)\end{array}$ \\
\hline Gender $_{\mathrm{m}}^{\dagger}$ & $\begin{array}{c}-0.065 * * * \\
(-2.714)\end{array}$ & $\begin{array}{c}-0.013 \\
(-0.496)\end{array}$ & $\begin{array}{c}0.005 \\
(0.100)\end{array}$ & $\begin{array}{c}-0.049 \\
(-0.856)\end{array}$ & $\begin{array}{c}0.005 * * \\
(2.247)\end{array}$ & $\begin{array}{l}0.007 * \\
(1.939)\end{array}$ \\
\hline $\operatorname{Age}_{\mathrm{m}, \mathrm{t}^{\dagger}}$ & $\begin{array}{l}-0.001 * * \\
(-2.491)\end{array}$ & $\begin{array}{c}-0.002 * * * \\
(-3.010)\end{array}$ & $\begin{array}{c}0.004 * * * \\
(4.065)\end{array}$ & $\begin{array}{c}0.006 * * * \\
(3.092)\end{array}$ & $\begin{array}{c}-0.000 \\
(-1.304)\end{array}$ & $\begin{array}{c}-0.000 * * * \\
(-3.672)\end{array}$ \\
\hline Degree $_{\mathrm{m}}^{\dagger}$ & $\begin{array}{c}-0.014 \\
(-0.463)\end{array}$ & $\begin{array}{c}-0.037 * * \\
(-2.224)\end{array}$ & $\begin{array}{c}0.041 \\
(0.638)\end{array}$ & $\begin{array}{l}-0.101^{*} \\
(-1.842)\end{array}$ & $\begin{array}{l}-0.000 \\
(-0.016)\end{array}$ & $\begin{array}{c}0.001 \\
(0.483)\end{array}$ \\
\hline Plain English $_{\mathrm{i}, \mathrm{t}}$ & $\begin{array}{c}0.022 * * * \\
(6.222)\end{array}$ & $\begin{array}{c}0.026^{* * * *} \\
(7.016)\end{array}$ & $\begin{array}{c}-0.128 * * * \\
(-15.215)\end{array}$ & $\begin{array}{c}-0.143 * * * \\
(-14.595)\end{array}$ & $\begin{array}{c}-0.003 * * * \\
(-9.030)\end{array}$ & $\begin{array}{l}-0.004 * * * \\
(-11.242)\end{array}$ \\
\hline Grammar error $_{i, t}$ & $\begin{array}{c}-0.038 * * * \\
(-3.852)\end{array}$ & $\begin{array}{c}-0.050 * * * \\
(-4.189)\end{array}$ & $\begin{array}{c}0.086 * * * \\
(2.929)\end{array}$ & $\begin{array}{c}0.111 * * * \\
(3.623)\end{array}$ & $\begin{array}{c}0.002^{* *} \\
(2.063)\end{array}$ & $\begin{array}{c}0.004 * * * \\
(4.953)\end{array}$ \\
\hline \multicolumn{7}{|c|}{ Firm call characteristics } \\
\hline $\log$ Words $_{\mathrm{i}, \mathrm{t}}$ & $\begin{array}{c}0.008 \\
(1.353)\end{array}$ & $\begin{array}{c}0.001 \\
(0.107)\end{array}$ & $\begin{array}{c}0.049 * * * \\
(4.109)\end{array}$ & $\begin{array}{c}0.059 * * * \\
(2.886)\end{array}$ & $\begin{array}{c}-0.003 * * * \\
(-3.339)\end{array}$ & $\begin{array}{c}-0.005^{* * * *} \\
(-3.310)\end{array}$ \\
\hline $\log _{\text {Participants }} \mathrm{i}_{\mathrm{i}, \mathrm{t}}$ & $\begin{array}{c}0.001 \\
(0.237)\end{array}$ & $\begin{array}{c}0.018 \\
(1.480)\end{array}$ & $\begin{array}{c}0.008 \\
(0.434)\end{array}$ & $\begin{array}{c}-0.003 \\
(-0.132)\end{array}$ & $\begin{array}{c}0.005 * * * \\
(4.649)\end{array}$ & $\begin{array}{c}0.005 * * \\
(2.077)\end{array}$ \\
\hline Size $_{i, t}$ & $\begin{array}{c}-0.004 \\
(-1.509)\end{array}$ & $\begin{array}{c}-0.012 * * * \\
(-4.042)\end{array}$ & $\begin{array}{c}0.017 * * * \\
(3.598)\end{array}$ & $\begin{array}{c}-0.002 \\
(-0.282)\end{array}$ & $\begin{array}{c}-0.000 \\
(-1.432)\end{array}$ & $\begin{array}{c}0.001 \\
(1.381)\end{array}$ \\
\hline $\mathrm{Q}_{\mathrm{i}, \mathrm{t}}$ & $\begin{array}{c}0.001 \\
(0.410)\end{array}$ & $\begin{array}{c}-0.000 \\
(-0.118)\end{array}$ & $\begin{array}{c}-0.003 \\
(-0.654)\end{array}$ & $\begin{array}{c}0.008 \\
(1.324)\end{array}$ & $\begin{array}{c}0.000 \\
(0.985)\end{array}$ & $\begin{array}{c}0.000 \\
(0.086)\end{array}$ \\
\hline Leverage $_{i, t}$ & $\begin{array}{c}-0.023 * * * \\
(-2.918)\end{array}$ & $\begin{array}{c}0.002 \\
(0.776)\end{array}$ & $\begin{array}{c}-0.009 \\
(-0.647)\end{array}$ & $\begin{array}{c}0.003 \\
(0.335)\end{array}$ & $\begin{array}{l}0.002^{*} \\
(1.651)\end{array}$ & $\begin{array}{c}0.000 \\
(0.882)\end{array}$ \\
\hline $\mathrm{ROA}_{\mathrm{i}, \mathrm{t}}$ & $\begin{array}{c}-0.006 \\
(-0.388)\end{array}$ & $\begin{array}{c}0.029 \\
(1.042)\end{array}$ & $\begin{array}{c}-0.037 \\
(-1.302)\end{array}$ & $\begin{array}{c}-0.074 \\
(-1.357)\end{array}$ & $\begin{array}{c}0.001 \\
(0.379)\end{array}$ & $\begin{array}{c}0.002 \\
(0.568)\end{array}$ \\
\hline ESUR $_{i, t}$ & $\begin{array}{c}0.053 * * * \\
(11.872)\end{array}$ & $\begin{array}{c}0.038 * * * \\
(4.114)\end{array}$ & $\begin{array}{c}0.004 \\
(0.296)\end{array}$ & $\begin{array}{c}-0.017 \\
(-0.694)\end{array}$ & $\begin{array}{l}-0.001 * \\
(-1.768)\end{array}$ & $\begin{array}{c}0.001 \\
(0.648)\end{array}$ \\
\hline Log analysts ${ }_{i, t}$ & $\begin{array}{c}0.001 \\
(0.246)\end{array}$ & $\begin{array}{c}0.007 \\
(0.760)\end{array}$ & $\begin{array}{c}-0.010 \\
(-1.059)\end{array}$ & $\begin{array}{c}0.004 \\
(0.309)\end{array}$ & $\begin{array}{c}-0.000 \\
(-0.690)\end{array}$ & $\begin{array}{c}-0.000 \\
(-0.032)\end{array}$ \\
\hline D_loss $\mathrm{i}_{\mathrm{i}, \mathrm{t}}$ & $\begin{array}{c}-0.034 * * * \\
(-5.225)\end{array}$ & $\begin{array}{c}-0.016 \\
(-1.547)\end{array}$ & $\begin{array}{c}-0.003 \\
(-0.194)\end{array}$ & $\begin{array}{c}-0.026 \\
(-1.617)\end{array}$ & $\begin{array}{c}-0.000 \\
(-0.318)\end{array}$ & $\begin{array}{c}-0.000 \\
(-0.290)\end{array}$ \\
\hline Year_end $i_{i, t}$ & $\begin{array}{c}-0.002 \\
(-0.227)\end{array}$ & $\begin{array}{c}-0.001 \\
(-0.189)\end{array}$ & $\begin{array}{c}0.001 \\
(0.119)\end{array}$ & $\begin{array}{c}-0.004 \\
(-0.287)\end{array}$ & $\begin{array}{c}0.002 * * * \\
(2.941)\end{array}$ & $\begin{array}{c}0.001 \\
(1.138)\end{array}$ \\
\hline Ret_fye $_{i, t}$ & $\begin{array}{c}0.009 * * * \\
(2.859)\end{array}$ & $\begin{array}{c}0.014 * * * \\
(4.887)\end{array}$ & $\begin{array}{c}-0.035^{* * *} \\
(-5.574)\end{array}$ & $\begin{array}{c}-0.023 * * \\
(-2.088)\end{array}$ & $\begin{array}{c}-0.001 \\
(-1.160)\end{array}$ & $\begin{array}{c}0.000 \\
(0.296)\end{array}$ \\
\hline
\end{tabular}




\begin{tabular}{|c|c|c|c|c|c|c|}
\hline \multicolumn{7}{|l|}{ Country characteristics } \\
\hline Lack of trust $\mathrm{c}_{\mathrm{c}(\mathrm{m})}$ & $\begin{array}{c}1.831 * * * \\
(4.160)\end{array}$ & $\begin{array}{c}-0.035 \\
(-0.213)\end{array}$ & $\begin{array}{c}0.122 \\
(0.218)\end{array}$ & $\begin{array}{c}-0.282 \\
(-0.807)\end{array}$ & $\begin{array}{l}-0.101^{*} \\
(-1.828)\end{array}$ & $\begin{array}{c}0.015 \\
(0.518)\end{array}$ \\
\hline Uncertainty avoidance $_{\mathrm{c}(\mathrm{m})}$ & $\begin{array}{c}-0.008 * * * \\
(-5.036)\end{array}$ & $\begin{array}{c}0.001 \\
(1.430)\end{array}$ & $\begin{array}{c}-0.003 \\
(-1.396)\end{array}$ & $\begin{array}{c}0.001 \\
(0.603)\end{array}$ & $\begin{array}{c}0.000^{*} \\
(1.894)\end{array}$ & $\begin{array}{c}-0.000 \\
(-0.327)\end{array}$ \\
\hline Market cap ${ }_{c(i), t}$ & $\begin{array}{c}0.004 * * * \\
(3.410)\end{array}$ & $\begin{array}{c}0.006 * * * \\
(5.752)\end{array}$ & $\begin{array}{c}-0.005 * * * \\
(-2.775)\end{array}$ & $\begin{array}{c}-0.002 \\
(-0.720)\end{array}$ & $\begin{array}{c}-0.000 * * * \\
(-3.769)\end{array}$ & $\begin{array}{c}-0.001 * * * \\
(-4.977)\end{array}$ \\
\hline Market return $_{\mathrm{c}(\mathrm{i}), \mathrm{t}}$ & $\begin{array}{c}-0.040 \\
(-0.957)\end{array}$ & $\begin{array}{r}-0.049 * * \\
(-1.999)\end{array}$ & $\begin{array}{c}0.048 * * * \\
(5.974)\end{array}$ & $\begin{array}{c}-0.040 \\
(-1.297)\end{array}$ & $\begin{array}{c}0.001 \\
(0.553)\end{array}$ & $\begin{array}{c}0.005 * * \\
(2.148)\end{array}$ \\
\hline Synchronicity $_{\mathrm{c}(\mathrm{i}), \mathrm{t}}$ & $\begin{array}{c}-0.468 * * * \\
(-4.362)\end{array}$ & $\begin{array}{c}-0.245 \\
(-1.365)\end{array}$ & $\begin{array}{c}0.433 * * * \\
(3.251)\end{array}$ & $\begin{array}{c}-0.004 \\
(-0.010)\end{array}$ & $\begin{array}{c}0.000 \\
(0.009)\end{array}$ & $\begin{array}{c}-0.002 \\
(-0.100)\end{array}$ \\
\hline Zero returns $_{\mathrm{c}(\mathrm{i}), \mathrm{t}}$ & $\begin{array}{c}0.133 \\
(1.138)\end{array}$ & $\begin{array}{c}0.239 * * * \\
(2.719)\end{array}$ & $\begin{array}{c}0.011 \\
(0.076)\end{array}$ & $\begin{array}{c}-0.118 \\
(-0.636)\end{array}$ & $\begin{array}{c}-0.007 \\
(-0.385)\end{array}$ & $\begin{array}{c}-0.042 * * \\
(-2.280)\end{array}$ \\
\hline $\operatorname{Law}_{\mathrm{c}(\mathrm{i})}$ & $\begin{array}{c}-0.001 \\
(-0.149)\end{array}$ & $\begin{array}{c}0.000 \\
(0.006)\end{array}$ & $\begin{array}{c}0.012 \\
(1.562)\end{array}$ & $\begin{array}{c}0.009 \\
(1.199)\end{array}$ & $\begin{array}{c}-0.001 \\
(-1.034)\end{array}$ & $\begin{array}{c}-0.000 \\
(-0.683)\end{array}$ \\
\hline \# of observations & 95,925 & 33,862 & 95,925 & 33,862 & 95,925 & 33,862 \\
\hline R-square & 0.0702 & 0.0783 & 0.0701 & 0.0803 & 0.0150 & 0.0217 \\
\hline Cluster & Firm, year & Firm, year & Firm, year & Firm, year & Firm, year & Firm, year \\
\hline Year FE & Yes & Yes & Yes & Yes & Yes & Yes \\
\hline Industry FE & Yes & Yes & Yes & Yes & Yes & Yes \\
\hline
\end{tabular}

Panel B: Only U.S. firms

\begin{tabular}{ccc} 
(1) Tone_Q\&A $\mathrm{i}_{\mathrm{i}, \mathrm{m}, \mathrm{t}}$ & (2) Self-reference_Q\&A $\mathrm{i}_{\mathrm{i}, \mathrm{m}, \mathrm{t}}$ & (3) Apologies_Q\&A $\mathrm{A}_{\mathrm{i}, \mathrm{m}, \mathrm{t}}$ \\
\hline $0.130^{* * *}$ & $0.203^{* * *}$ & $-0.019^{* * *}$ \\
$(2.989)$ & $(2.267)$ & $(-3.163)$ \\
& & \\
19,858 & 19,858 & 19,858 \\
0.0712 & 0.0916 & 0.0163 \\
Firm, year & Firm, year & Firm, year \\
Yes & Yes & Yes \\
& & \\
Yes & Yes & Yes \\
Yes & Yes & Yes \\
Yes & Yes & Yes \\
US & US & US
\end{tabular}

Notes: This table presents coefficient estimates from the OLS regressions of disclosure attributes on various country-, firm-, and conference-call-level characteristics, separately for observations where the manager is of the same ethnicity as the dominant one in the country where is firm is headquartered (local) and where the manager is from a different ethnicity as the dominant local one (cross-cultural). Panel A includes observations from all countries in our sample. Panel B restricts the sample to only firms headquartered in the U.S. There, only cross-cultural observations are reported, because there is no variation in Individualism among local managers. The unit of analysis is an individual manager $(m)$ in an earnings conference call- quarter $(i, t)$. All variables are defined in Appendix B. T-statistics are reported in parentheses below the regression coefficients. We cluster standards errors at the firm and year levels. *, **, and ${ }^{* * *}$ denote significance at the $10 \%, 5 \%$, and $1 \%$ levels, respectively. ${ }^{\dagger}$ Denotes variables where we include an interaction term with the underlying variable and an indicator for missing observations in the regression model. 
Table 6 Firm's ethnic diversity and standard deviation in disclosure attributes of the management team

Panel A: Cross country sample

\begin{tabular}{|c|c|c|c|}
\hline & $\begin{array}{c}\text { Standard } \\
\text { deviation_tone }_{\mathrm{i}, \mathrm{t}}\end{array}$ & $\begin{array}{c}\text { Standard deviation } \\
\text { _self-reference }{ }_{i, t}\end{array}$ & $\begin{array}{c}\text { Standard deviation } \\
\text { _apologies } \\
\end{array}$ \\
\hline Ethnic diversity & $\begin{array}{c}0.033 * * * \\
(9.438)\end{array}$ & $\begin{array}{l}0.061 * * * \\
(7.744)\end{array}$ & $\begin{array}{c}0.006 * * * \\
(6.664)\end{array}$ \\
\hline Plain English ${ }_{i, m, t}$ & $\begin{array}{c}-0.013 * * * \\
(-6.610)\end{array}$ & $\begin{array}{l}-0.061 * * * \\
(-14.849)\end{array}$ & $\begin{array}{c}-0.005 * * * \\
(-9.360)\end{array}$ \\
\hline Grammar error $_{\mathrm{im}, \mathrm{t}}$ & $\begin{array}{c}0.023 * * * \\
(4.399)\end{array}$ & $\begin{array}{c}0.069 * * * \\
(8.962)\end{array}$ & $\begin{array}{c}0.008 * * * \\
(6.206)\end{array}$ \\
\hline $\log _{\text {Words }} \mathrm{w}_{\mathrm{i}, \mathrm{t}}$ & $\begin{array}{l}-0.078 * * * \\
(-15.334)\end{array}$ & $\begin{array}{l}-0.103 * * * \\
(-14.233)\end{array}$ & $\begin{array}{l}-0.006 * * * \\
(-4.608)\end{array}$ \\
\hline Log Participants $_{\mathrm{i}, \mathrm{t}}$ & $\begin{array}{c}0.005 \\
(0.891)\end{array}$ & $\begin{array}{c}0.007 \\
(0.556)\end{array}$ & $\begin{array}{l}0.007 * * * \\
(5.602)\end{array}$ \\
\hline Size $_{i, t}$ & $\begin{array}{l}0.010 * * * \\
(6.709)\end{array}$ & $\begin{array}{c}0.013 * * * \\
(3.821)\end{array}$ & $\begin{array}{c}0.001 * * * \\
(3.378)\end{array}$ \\
\hline $\mathrm{Q}_{\mathrm{i}, \mathrm{t}}$ & $\begin{array}{c}-0.001 \\
(-0.637)\end{array}$ & $\begin{array}{c}-0.002 \\
(-0.691)\end{array}$ & $\begin{array}{c}-0.000 \\
(-0.639)\end{array}$ \\
\hline Leverage $_{i, t}$ & $\begin{array}{l}-0.006^{*} \\
(-1.882)\end{array}$ & $\begin{array}{c}-0.005 \\
(-0.687)\end{array}$ & $\begin{array}{c}0.001 \\
(1.170)\end{array}$ \\
\hline $\mathrm{ROA}_{i, t}$ & $\begin{array}{c}-0.004 \\
(-0.388)\end{array}$ & $\begin{array}{c}-0.012 \\
(-0.502)\end{array}$ & $\begin{array}{c}0.003 \\
(1.168)\end{array}$ \\
\hline ESUR $_{\mathrm{i}, \mathrm{t}}$ & $\begin{array}{l}-0.019 * * \\
(-2.206)\end{array}$ & $\begin{array}{c}-0.014 \\
(-1.336)\end{array}$ & $\begin{array}{c}-0.001 \\
(-0.789)\end{array}$ \\
\hline $\log _{\text {analysts }}$ it, & $\begin{array}{c}0.000 \\
(0.088)\end{array}$ & $\begin{array}{c}-0.003 \\
(-0.477)\end{array}$ & $\begin{array}{c}0.000 \\
(0.225)\end{array}$ \\
\hline D_loss $_{i, t}$ & $\begin{array}{c}0.004 \\
(0.720)\end{array}$ & $\begin{array}{c}0.011 \\
(1.072)\end{array}$ & $\begin{array}{c}0.001 \\
(1.048)\end{array}$ \\
\hline Ret_fye $_{i, t}$ & $\begin{array}{c}-0.004 * * * \\
(-2.992)\end{array}$ & $\begin{array}{c}-0.015^{* * *} * \\
(-3.711)\end{array}$ & $\begin{array}{c}-0.001 \\
(-1.021)\end{array}$ \\
\hline volatility & $\begin{array}{c}0.234 * * \\
(2.045)\end{array}$ & $\begin{array}{c}0.285 \\
(1.050)\end{array}$ & $\begin{array}{c}-0.021 \\
(-0.670)\end{array}$ \\
\hline stdni & $\begin{array}{c}0.053 * * * \\
(2.780)\end{array}$ & $\begin{array}{c}0.024 \\
(0.784)\end{array}$ & $\begin{array}{c}0.001 \\
(0.361)\end{array}$ \\
\hline Lack of trust $t_{c(m), t}$ & $\begin{array}{c}-0.115 \\
(-1.515)\end{array}$ & $\begin{array}{c}-0.322 * * * \\
(-2.842)\end{array}$ & $\begin{array}{c}0.007 \\
(0.339)\end{array}$ \\
\hline Uncertainty avoidance $_{\mathrm{c}(\mathrm{m})}$ & $\begin{array}{l}-0.001 * * \\
(-2.458)\end{array}$ & $\begin{array}{l}-0.001 * \\
(-1.858)\end{array}$ & $\begin{array}{c}-0.000 \\
(-1.283)\end{array}$ \\
\hline accrual & $\begin{array}{c}0.020 \\
(1.320)\end{array}$ & $\begin{array}{c}0.024 \\
(0.784)\end{array}$ & $\begin{array}{c}0.004 \\
(1.052)\end{array}$ \\
\hline Market $\operatorname{cap}_{\mathrm{c}(\mathrm{i}), \mathrm{t}}$ & $\begin{array}{c}0.001 \\
(0.916)\end{array}$ & $\begin{array}{c}0.000 \\
(0.028)\end{array}$ & $\begin{array}{c}-0.001 * * * \\
(-4.296)\end{array}$ \\
\hline Market return $_{\mathrm{c}(\mathrm{i}), \mathrm{t}}$ & $\begin{array}{c}-0.018 \\
(-0.919)\end{array}$ & $\begin{array}{c}0.038 \\
(1.357)\end{array}$ & $\begin{array}{c}0.007 \\
(0.999)\end{array}$ \\
\hline Synchronicity $_{\mathrm{c}(\mathrm{i}), \mathrm{t}}$ & $\begin{array}{c}-0.020 \\
(-0.212)\end{array}$ & $\begin{array}{c}-0.056 \\
(-0.375)\end{array}$ & $\begin{array}{c}-0.023 \\
(-0.818)\end{array}$ \\
\hline Zero returns $_{\mathrm{c}(\mathrm{i}), \mathrm{t}}$ & $\begin{array}{c}0.038 \\
(0.838)\end{array}$ & $\begin{array}{c}0.109 \\
(1.273)\end{array}$ & $\begin{array}{c}-0.049 * * * \\
(-2.643)\end{array}$ \\
\hline $\operatorname{Law}_{\mathrm{c}(\mathrm{i}), \mathrm{t}}$ & $\begin{array}{c}-0.001 \\
(-0.511)\end{array}$ & $\begin{array}{c}-0.000 \\
(-0.063)\end{array}$ & $\begin{array}{c}-0.001 \\
(-1.074)\end{array}$ \\
\hline Observations & 18,454 & 18,454 & 18,454 \\
\hline
\end{tabular}




\begin{tabular}{lccc} 
R-squared & 0.0700 & 0.0606 & 0.0352 \\
Cluster & Firm, Year & Firm, Year & Firm, Year \\
Industry FE & Yes & Yes & Yes \\
Year FR & Yes & Yes & Yes \\
Transcripts & Q\&A & Q\&A & Q\&A \\
\hline
\end{tabular}

Panel B: Only U.S. firms

\begin{tabular}{|c|c|c|c|}
\hline & $\begin{array}{c}\text { Standard deviation } \\
\text { tone }\end{array}$ & $\begin{array}{c}\begin{array}{c}\text { Standard deviation } \\
\text { self-reference }\end{array} \text { i,t } \\
\end{array}$ & $\begin{array}{c}\text { Standard deviation } \\
\text { apologies } \\
\text { apot, }\end{array}$ \\
\hline Ethnic diversity & $\begin{array}{c}0.029 * * * \\
(8.393)\end{array}$ & $\begin{array}{c}0.048 * * * \\
(5.728)\end{array}$ & $\begin{array}{c}0.006 * * * \\
(7.037)\end{array}$ \\
\hline Observations & 12,617 & 12,617 & 12,617 \\
\hline R-squared & 0.0825 & 0.0723 & 0.0200 \\
\hline Cluster & Firm, Year & Firm, Year & Firm, Year \\
\hline Industry FE & Yes & Yes & Yes \\
\hline Year FE & Yes & Yes & Yes \\
\hline Transcripts & Q\&A & Q\&A & Q\&A \\
\hline
\end{tabular}

Notes: This table presents coefficient estimates from the OLS regressions of the standard deviation of disclosure attributes on various country-, firm-, and conference-call-level characteristics. Panel A includes observations from all countries in our sample. Panel B restricts the sample to only firms headquartered in the U.S. The unit of analysis is a firm in a fiscal year $(i, t)$. All variables are defined in Appendix B. T-statistics are reported in parentheses below the regression coefficients. We cluster standards errors at the firm and year levels. ${ }^{*},{ }^{* *}$, and ${ }^{* * *}$ denote significance at the $10 \%, 5 \%$, and $1 \%$ levels, respectively. ${ }^{\dagger}$ Denotes variables where we include an interaction term with the underlying variable and an indicator for missing observations in the regression model. 
Table 7 Effect of manager's ethnic background for management discussion vs Q\&A portion of the calls

Panel A: Cross-country sample

\begin{tabular}{|c|c|c|c|c|c|c|c|c|c|}
\hline \multirow{3}{*}{ Variables } & \multicolumn{3}{|c|}{ Tone $_{\mathrm{i}, \mathrm{m}, \mathrm{t}}$} & \multicolumn{3}{|c|}{ Self-reference $e_{i, m, t}$} & \multicolumn{3}{|c|}{ Apologies $_{i, m, t}$} \\
\hline & (1) $\mathrm{Q} \& \mathrm{~A}$ & (2) & (3) All & (4) Q\&A & (5) & (6) All & (7) $\mathrm{Q} \& \mathrm{~A}$ & (8) & (9) All \\
\hline & $\begin{array}{c}\text { Coeff } \\
\text { (t-stat) }\end{array}$ & $\begin{array}{c}\text { Coeff } \\
(t \text {-stat })\end{array}$ & $\begin{array}{c}\text { Coeff } \\
(t \text {-stat })\end{array}$ & $\begin{array}{c}\text { Coeff } \\
(t-\text { stat })\end{array}$ & $\begin{array}{c}\text { Coeff } \\
(t \text {-stat })\end{array}$ & $\begin{array}{c}\text { Coeff } \\
(t \text {-stat })\end{array}$ & $\begin{array}{c}\text { Coeff } \\
(t-\text { stat })\end{array}$ & $\begin{array}{c}\text { Coeff } \\
(t \text {-stat })\end{array}$ & $\begin{array}{c}\text { Coeff } \\
(t \text {-stat })\end{array}$ \\
\hline \multicolumn{10}{|c|}{ Manager-call characteristics } \\
\hline Individualism $_{\mathrm{m}}$ & $\begin{array}{c}0.091 * * * \\
(4.507)\end{array}$ & $\begin{array}{c}-0.065^{* * *} \\
(-3.719)\end{array}$ & $\begin{array}{c}0.019 \\
(1.208)\end{array}$ & $\begin{array}{c}0.174 * * * \\
(4.470)\end{array}$ & $\begin{array}{c}-0.028 \\
(-0.938)\end{array}$ & $\begin{array}{l}0.054 * \\
(1.779)\end{array}$ & $\begin{array}{c}-0.015 * * * \\
(-6.203)\end{array}$ & $\begin{array}{c}-0.001 * * \\
(-2.460)\end{array}$ & $\begin{array}{c}-0.015 * * * \\
(-5.145)\end{array}$ \\
\hline $\mathrm{CEO}_{\mathrm{m}}$ & $\begin{array}{c}0.169 * * * \\
(34.580)\end{array}$ & $\begin{array}{c}0.270 * * * \\
(29.573)\end{array}$ & $\begin{array}{c}0.219 * * * \\
(35.024)\end{array}$ & $\begin{array}{c}0.208 * * * \\
(17.421)\end{array}$ & $\begin{array}{c}0.168 * * * \\
(13.993)\end{array}$ & $\begin{array}{c}0.250 * * * \\
(24.106)\end{array}$ & $\begin{array}{c}-0.006 * * * \\
(-12.355)\end{array}$ & $\begin{array}{c}0.000 \\
(0.484)\end{array}$ & $\begin{array}{c}-0.005 * * * \\
(-10.644)\end{array}$ \\
\hline Gender $_{\mathrm{m}}^{\dagger}$ & $\begin{array}{c}-0.051 * * * \\
(-2.836)\end{array}$ & $\begin{array}{c}-0.015 \\
(-0.925)\end{array}$ & $\begin{array}{c}-0.034 * * \\
(-2.134)\end{array}$ & $\begin{array}{c}-0.009 \\
(-0.237)\end{array}$ & $\begin{array}{c}0.033 \\
(1.467)\end{array}$ & $\begin{array}{c}-0.035 \\
(-1.626)\end{array}$ & $\begin{array}{c}0.006^{* * *} * \\
(2.941)\end{array}$ & $\begin{array}{c}0.000 \\
(0.896)\end{array}$ & $\begin{array}{l}0.002 * \\
(1.798)\end{array}$ \\
\hline Age $_{\mathrm{m}, \mathrm{t}^{\dagger}}$ & $\begin{array}{c}-0.001 * * * \\
(-4.142)\end{array}$ & $\begin{array}{c}-0.001 * * * \\
(-3.200)\end{array}$ & $\begin{array}{c}-0.002 * * * \\
(-4.297)\end{array}$ & $\begin{array}{c}0.005^{* * *} * \\
(4.730)\end{array}$ & $\begin{array}{c}0.005^{* * *} * \\
(7.107)\end{array}$ & $\begin{array}{c}0.005 * * * \\
(6.464)\end{array}$ & $\begin{array}{c}-0.000 * * * \\
(-2.782)\end{array}$ & $\begin{array}{c}0.000 * * * \\
(2.861)\end{array}$ & $\begin{array}{c}0.000 \\
(0.428)\end{array}$ \\
\hline Degree $_{\mathrm{m}}^{\dagger}$ & $\begin{array}{c}-0.019 \\
(-0.975)\end{array}$ & $\begin{array}{c}0.018 \\
(0.846)\end{array}$ & $\begin{array}{c}-0.002 \\
(-0.116)\end{array}$ & $\begin{array}{c}-0.032 \\
(-0.683)\end{array}$ & $\begin{array}{c}0.066 \\
(1.324)\end{array}$ & $\begin{array}{c}0.019 \\
(0.572)\end{array}$ & $\begin{array}{c}0.000 \\
(0.000)\end{array}$ & $\begin{array}{c}0.001 \\
(1.297)\end{array}$ & $\begin{array}{c}0.001 \\
(0.614)\end{array}$ \\
\hline \# of observations & 129,787 & 105,311 & 129,787 & 129,787 & 105,311 & 129,787 & 129,787 & 105,311 & 129,787 \\
\hline R-square & 0.0694 & 0.1534 & 0.1263 & 0.0715 & 0.0610 & 0.0908 & 0.0162 & 0.0142 & 0.0129 \\
\hline Cluster & Firm, year & Firm-Year & Firm-Year & Firm, year & Firm-Year & Firm-Year & Firm, year & Firm-Year & Firm-Year \\
\hline Controls in Table 4 & Yes & Yes & Yes & Yes & Yes & Yes & Yes & Yes & Yes \\
\hline Year FE & Yes & Yes & Yes & Yes & Yes & Yes & Yes & Yes & Yes \\
\hline Industry FE & Yes & Yes & Yes & Yes & Yes & Yes & Yes & Yes & Yes \\
\hline
\end{tabular}

Notes: This table presents coefficient estimates from the OLS regressions of disclosure attributes on various country-, firm-, and conference-call-level characteristics. Panel A includes observations from all countries in our sample. Panel B restricts the sample to only firms headquartered in the U.S. The unit of analysis is an individual manager $(m)$ in an earnings conference call- quarter $(i, t)$. All variables are defined in Appendix B. T-statistics are reported in parentheses below the regression coefficients. We cluster standards errors at the firm and year levels. ${ }^{*},{ }^{* *}$, and ${ }^{* * *}$ denote significance at the $10 \%, 5 \%$, and $1 \%$ levels, respectively. ${ }^{\dagger}$ Denotes variables where we include an interaction term with the underlying variable and an indicator for missing observations in the regression model. 
Table 7 (Continued)

Panel B Only U.S. firms

\begin{tabular}{|c|c|c|c|c|c|c|c|c|c|}
\hline & \multicolumn{3}{|c|}{ Tone $_{i, m, t}$} & \multicolumn{3}{|c|}{ Self-reference $_{i, m, t}$} & \multicolumn{3}{|c|}{ Apologies $_{\mathrm{i}, \mathrm{m}, \mathrm{t}}$} \\
\hline & (1) Q\&A & (2) MD & (3) All & (4) Q\&A & (5) MD & (6) All & (7) $\mathrm{Q} \& \mathrm{~A}$ & (8) MD & (9) All \\
\hline & $\begin{array}{c}\text { Coeff } \\
(t \text {-stat })\end{array}$ & $\begin{array}{r}\text { Coeff } \\
(t-\text { stat })\end{array}$ & $\begin{array}{c}\text { Coeff } \\
(t-s t a t)\end{array}$ & $\begin{array}{c}\text { Coeff } \\
(t \text {-stat })\end{array}$ & $\begin{array}{c}\text { Coeff } \\
(t-\text { stat })\end{array}$ & $\begin{array}{r}\text { Coeff } \\
(t-s t a t)\end{array}$ & $\begin{array}{r}\text { Coeff } \\
(t \text {-stat })\end{array}$ & $\begin{array}{r}\text { Coeff } \\
(t-\text { stat })\end{array}$ & $\begin{array}{r}\text { Coeff } \\
(t-s t a t)\end{array}$ \\
\hline Individualism $_{m}$ & $\begin{array}{c}0.058 * * * \\
(2.676)\end{array}$ & $\begin{array}{c}-0.068 * * * \\
(-3.124)\end{array}$ & $\begin{array}{c}-0.006 \\
(-0.360)\end{array}$ & $\begin{array}{c}0.172 * * * \\
(3.834)\end{array}$ & $\begin{array}{c}0.064 * * \\
(2.040)\end{array}$ & $\begin{array}{c}0.075 * * \\
(2.236)\end{array}$ & $\begin{array}{c}-0.014 * * * \\
(-5.258)\end{array}$ & $\begin{array}{c}-0.000 \\
(-0.964)\end{array}$ & $\begin{array}{c}-0.012 * * * \\
(-3.161)\end{array}$ \\
\hline $\mathrm{CEO}_{\mathrm{m}}$ & $\begin{array}{c}0.168 * * * \\
(27.914)\end{array}$ & $\begin{array}{c}0.291 * * * \\
(27.431)\end{array}$ & $\begin{array}{l}0.227 * * * \\
(30.225)\end{array}$ & $\begin{array}{c}0.188 * * * \\
(14.972)\end{array}$ & $\begin{array}{c}0.209 * * * \\
(17.807)\end{array}$ & $\begin{array}{c}0.274 * * * \\
(25.181)\end{array}$ & $\begin{array}{c}-0.006 * * * \\
(-12.261)\end{array}$ & $\begin{array}{c}-0.000 \\
(-0.244)\end{array}$ & $\begin{array}{c}-0.003 * * * \\
(-8.073)\end{array}$ \\
\hline Gender $_{\mathrm{m}}^{\dagger}$ & $\begin{array}{c}-0.031 \\
(-1.554)\end{array}$ & $\begin{array}{c}-0.003 \\
(-0.189)\end{array}$ & $\begin{array}{c}-0.016 \\
(-1.011)\end{array}$ & $\begin{array}{c}-0.041 \\
(-0.848)\end{array}$ & $\begin{array}{c}0.017 \\
(0.792)\end{array}$ & $\begin{array}{c}-0.053 * * \\
(-2.279)\end{array}$ & $\begin{array}{c}0.006 * * * \\
(3.165)\end{array}$ & $\begin{array}{c}0.001 \\
(1.219)\end{array}$ & $\begin{array}{c}0.003 * * \\
(2.219)\end{array}$ \\
\hline Age $_{m, t^{\dagger}}$ & $\begin{array}{c}-0.001 * * * \\
(-3.879)\end{array}$ & $\begin{array}{c}-0.002 * * * \\
(-4.044)\end{array}$ & $\begin{array}{c}-0.002 * * * \\
(-4.607)\end{array}$ & $\begin{array}{c}0.004 * * * \\
(4.299)\end{array}$ & $\begin{array}{c}0.005 * * * \\
(5.693)\end{array}$ & $\begin{array}{c}0.004 * * * \\
(5.273)\end{array}$ & $\begin{array}{c}-0.000 * * \\
(-2.369)\end{array}$ & $\begin{array}{c}0.000 * * * \\
(3.076)\end{array}$ & $\begin{array}{c}-0.000 \\
(-0.720)\end{array}$ \\
\hline Degree $_{\mathrm{m}}^{\dagger}$ & $\begin{array}{c}0.009 \\
(0.508)\end{array}$ & $\begin{array}{c}0.056 * * \\
(2.235)\end{array}$ & $\begin{array}{c}0.043 * * \\
(2.370)\end{array}$ & $\begin{array}{c}-0.080 \\
(-1.298)\end{array}$ & $\begin{array}{c}-0.021 \\
(-0.559)\end{array}$ & $\begin{array}{c}-0.056 \\
(-1.266)\end{array}$ & $\begin{array}{c}0.000 \\
(0.018)\end{array}$ & $\begin{array}{c}0.001 \\
(1.252)\end{array}$ & $\begin{array}{c}0.000 \\
(0.115)\end{array}$ \\
\hline Observations & 88,116 & 73,292 & 88,116 & 88,116 & 73,292 & 88,116 & 88,116 & 73,292 & 88,116 \\
\hline R-squared & 0.0606 & 0.1827 & 0.1419 & 0.0718 & 0.0756 & 0.1012 & 0.0113 & 0.0044 & 0.0071 \\
\hline $\begin{array}{l}\text { Controls in } \\
\text { Table } 4\end{array}$ & Yes & Yes & Yes & Yes & Yes & Yes & Yes & Yes & Yes \\
\hline Year FE & Yes & Yes & Yes & Yes & Yes & Yes & Yes & Yes & Yes \\
\hline Industry FE & Yes & Yes & Yes & Yes & Yes & Yes & Yes & Yes & Yes \\
\hline Sample & US only & US only & US only & US only & US only & US only & US only & US only & US only \\
\hline
\end{tabular}

Notes: This table presents coefficient estimates from the OLS regressions of disclosure attributes on various country-, firm-, and conference-call-level characteristics. Panel A includes observations from all countries in our sample. Panel B restricts the sample to only firms headquartered in the U.S. The unit of analysis is an individual manager $(m)$ in an earnings conference call- quarter $(i, t)$. All variables are defined in Appendix B. T-statistics are reported in parentheses below the regression coefficients. We cluster standards errors at the firm and year levels. ${ }^{*},{ }^{* *}$, and ${ }^{* * *}$ denote significance at the $10 \%, 5 \%$, and $1 \%$ levels, respectively. ${ }^{\dagger}$ Denotes variables where we include an interaction term with the underlying variable and an indicator for missing observations in the regression model. 
Table 8 Capital market reaction to disclosure tone following the call: Intra-day returns

\begin{tabular}{|c|c|c|c|c|c|c|}
\hline \multirow[t]{2}{*}{ Dependent Variable: } & \multicolumn{2}{|c|}{$\begin{array}{l}\text { Intra-day returns during the } \\
\qquad \& A s\end{array}$} & \multicolumn{2}{|c|}{ Intra-day returns during the MDs } & \multicolumn{2}{|c|}{$\begin{array}{l}\text { Intra-day returns during the } Q \& A \text { and } \\
M D s\end{array}$} \\
\hline & $(1)$ & $(2)$ & (3) & (4) & $(5)$ & $(6)$ \\
\hline Tone_Q\&A $\mathrm{A}_{\mathrm{i}, \mathrm{t}}$ & $\begin{array}{c}0.15 * * * \\
(2.80)\end{array}$ & $\begin{array}{c}0.16 * * * \\
(2.64)\end{array}$ & & & & \\
\hline $\begin{array}{l}\text { Tone_Q\&A } \mathrm{A}_{\mathrm{i}, \mathrm{t}} \\
\times \text { Low individualism indicator }\end{array}$ & & $\begin{array}{c}-0.06 \\
(-0.83)\end{array}$ & & & & \\
\hline Tone_MD ${ }_{i, t}$ & & & $\begin{array}{l}0.10 * * * \\
(2.68)\end{array}$ & $\begin{array}{l}0.09 * * \\
(1.99)\end{array}$ & & \\
\hline $\begin{array}{l}\text { Tone_MD }{ }_{\mathrm{i}, \mathrm{t}} \\
\times \text { Low individualism indicator }\end{array}$ & & & & $\begin{array}{c}0.07 \\
(0.66)\end{array}$ & & \\
\hline Tone_all $_{\mathrm{i}, \mathrm{t}}$ & & & & & $\begin{array}{c}0.34 * * * \\
(3.79)\end{array}$ & $\begin{array}{l}0.31 * * * \\
(3.20)\end{array}$ \\
\hline $\begin{array}{l}\text { Tone_all } \mathrm{i,t} \\
\times \text { Low individualism indicator }\end{array}$ & & & & & & $\begin{array}{c}0.20 \\
(0.93)\end{array}$ \\
\hline Low individualism indicator & & $\begin{array}{c}0.00 \\
(0.08)\end{array}$ & & $\begin{array}{c}0.02 \\
(0.38)\end{array}$ & & $\begin{array}{c}-0.04 \\
(-0.48)\end{array}$ \\
\hline Firm characteristics & & & & & & \\
\hline Size $_{i, t}$ & $\begin{array}{c}-0.01 \\
(-0.39)\end{array}$ & $\begin{array}{c}-0.01 \\
(-0.39)\end{array}$ & $\begin{array}{c}-0.01 \\
(-0.75)\end{array}$ & $\begin{array}{c}-0.01 \\
(-0.77)\end{array}$ & $\begin{array}{l}-0.02 \\
(-0.73)\end{array}$ & $\begin{array}{c}-0.02 \\
(-0.71)\end{array}$ \\
\hline $\mathrm{Q}_{\mathrm{i}, \mathrm{t}}$ & $\begin{array}{l}-0.01 \\
(-0.42)\end{array}$ & $\begin{array}{c}-0.01 \\
(-0.42)\end{array}$ & $\begin{array}{c}0.01 \\
(0.34)\end{array}$ & $\begin{array}{c}0.01 \\
(0.32)\end{array}$ & $\begin{array}{l}-0.00 \\
(-0.01)\end{array}$ & $\begin{array}{l}-0.00 \\
(-0.03)\end{array}$ \\
\hline Leverage $_{\mathrm{i}, \mathrm{t}}$ & $\begin{array}{l}0.11^{*} \\
(1.90)\end{array}$ & $\begin{array}{l}0.11^{*} \\
(1.90)\end{array}$ & $\begin{array}{l}-0.00 \\
(-0.05)\end{array}$ & $\begin{array}{c}-0.00 \\
(-0.07)\end{array}$ & $\begin{array}{c}0.10 \\
(1.56)\end{array}$ & $\begin{array}{c}0.10 \\
(1.56)\end{array}$ \\
\hline $\mathrm{ROA}_{\mathrm{i}, \mathrm{t}}$ & $\begin{array}{c}0.23 \\
(1.36)\end{array}$ & $\begin{array}{c}0.23 \\
(1.37)\end{array}$ & $\begin{array}{l}-0.04 \\
(-0.19)\end{array}$ & $\begin{array}{c}-0.05 \\
(-0.20)\end{array}$ & $\begin{array}{c}0.11 \\
(0.45)\end{array}$ & $\begin{array}{c}0.11 \\
(0.44)\end{array}$ \\
\hline ESUR $_{i, t}$ & $\begin{array}{c}0.01 \\
(0.14)\end{array}$ & $\begin{array}{l}0.01 \\
(0.15)\end{array}$ & $\begin{array}{l}0.10^{*} \\
(1.92)\end{array}$ & $\begin{array}{l}0.10^{*} \\
(1.93)\end{array}$ & $\begin{array}{c}0.08 \\
(1.04)\end{array}$ & $\begin{array}{c}0.08 \\
(1.04)\end{array}$ \\
\hline $\log \_a n a l y s t s_{i, t}$ & $\begin{array}{c}-0.02 \\
(-0.49)\end{array}$ & $\begin{array}{c}-0.02 \\
(-0.50)\end{array}$ & $\begin{array}{c}0.00 \\
(0.04)\end{array}$ & $\begin{array}{c}0.00 \\
(0.06)\end{array}$ & $\begin{array}{c}-0.02 \\
(-0.41)\end{array}$ & $\begin{array}{c}-0.02 \\
(-0.41)\end{array}$ \\
\hline D_loss ${ }_{i, t}$ & $\begin{array}{l}-0.01 \\
(-0.28)\end{array}$ & $\begin{array}{c}-0.01 \\
(-0.28)\end{array}$ & $\begin{array}{c}0.08 * \\
(1.69)\end{array}$ & $\begin{array}{l}0.08 * \\
(1.69)\end{array}$ & $\begin{array}{c}0.06 \\
(1.06)\end{array}$ & $\begin{array}{c}0.06 \\
(1.06)\end{array}$ \\
\hline Year_end ${ }_{i, t}$ & $\begin{array}{c}-0.01 \\
(-0.56)\end{array}$ & $\begin{array}{c}-0.02 \\
(-0.57)\end{array}$ & $\begin{array}{c}0.08 * * \\
(2.36)\end{array}$ & $\begin{array}{c}0.08 * * \\
(2.36)\end{array}$ & $\begin{array}{c}0.06 \\
(1.37)\end{array}$ & $\begin{array}{c}0.06 \\
(1.37)\end{array}$ \\
\hline Ret_fye $_{i, t}$ & $\begin{array}{c}-0.05 \\
(-1.55)\end{array}$ & $\begin{array}{c}-0.05 \\
(-1.55)\end{array}$ & $\begin{array}{c}0.01 \\
(0.31)\end{array}$ & $\begin{array}{c}0.01 \\
(0.31)\end{array}$ & $\begin{array}{c}-0.03 \\
(-0.73)\end{array}$ & $\begin{array}{c}-0.03 \\
(-0.72)\end{array}$ \\
\hline $\log _{-}$words $_{\mathrm{i}, \mathrm{t}}$ & $\begin{array}{c}-0.02 \\
(-0.57)\end{array}$ & $\begin{array}{c}-0.02 \\
(-0.59)\end{array}$ & $\begin{array}{c}0.07 * * \\
(1.98)\end{array}$ & $\begin{array}{c}0.07 * * \\
(2.08)\end{array}$ & $\begin{array}{c}0.04 \\
(0.81)\end{array}$ & $\begin{array}{c}0.04 \\
(0.83)\end{array}$ \\
\hline
\end{tabular}




\begin{tabular}{|c|c|c|c|c|c|c|}
\hline Returns volatility ${ }_{i, t}$ & $\begin{array}{c}0.44 \\
(0.33)\end{array}$ & $\begin{array}{c}0.45 \\
(0.34)\end{array}$ & $\begin{array}{c}-0.61 \\
(-0.44)\end{array}$ & $\begin{array}{c}-0.65 \\
(-0.48)\end{array}$ & $\begin{array}{c}-1.84 \\
(-0.67)\end{array}$ & $\begin{array}{c}-1.84 \\
(-0.67)\end{array}$ \\
\hline \multirow[t]{2}{*}{ Earnings volatility ${ }_{i, t}$} & 0.04 & 0.04 & $-0.51 * *$ & $-0.52 * *$ & -0.42 & $-0.42^{*}$ \\
\hline & $(0.25)$ & $(0.26)$ & $(-2.13)$ & $(-2.15)$ & $(-1.63)$ & $(-1.65)$ \\
\hline \multirow[t]{2}{*}{ Replag $_{\mathrm{i}, \mathrm{t}}$} & 0.00 & 0.00 & $-0.00 * * *$ & $-0.00 * * *$ & -0.00 & -0.00 \\
\hline & $(0.60)$ & $(0.60)$ & $(-2.61)$ & $(-2.62)$ & $(-0.77)$ & $(-0.76)$ \\
\hline \multirow[t]{2}{*}{ Accrual $_{i, t}$} & 0.03 & 0.03 & -0.26 & -0.26 & -0.04 & -0.04 \\
\hline & $(0.20)$ & $(0.21)$ & $(-1.36)$ & $(-1.34)$ & $(-0.17)$ & $(-0.17)$ \\
\hline \multirow[t]{2}{*}{ Participants $_{\mathrm{i}, \mathrm{t}}$} & -0.02 & -0.02 & -0.06 & -0.06 & -0.07 & -0.07 \\
\hline & $(-0.31)$ & $(-0.30)$ & $(-1.54)$ & $(-1.57)$ & $(-1.08)$ & $(-1.11)$ \\
\hline \multirow[t]{2}{*}{ Grammar errors, $\mathrm{t}$} & -0.00 & -0.00 & 0.00 & 0.00 & 0.00 & 0.00 \\
\hline & $(-0.34)$ & $(-0.34)$ & $(0.03)$ & $(0.03)$ & $(0.26)$ & $(0.26)$ \\
\hline \multirow[t]{2}{*}{ Plain English ${ }_{\mathrm{i}, \mathrm{t}}$} & $-0.02 * *$ & $-0.02 * *$ & -0.01 & -0.01 & $-0.04 * *$ & $-0.04 * *$ \\
\hline & $(-2.11)$ & $(-2.11)$ & $(-0.85)$ & $(-0.87)$ & $(-2.06)$ & $(-2.09)$ \\
\hline \multirow[t]{2}{*}{ Returns day before $_{\mathrm{i}, \mathrm{t}}$} & $-0.84 * * *$ & $-0.84 * * *$ & $-0.64 * *$ & $-0.64 * *$ & $-1.08 * * *$ & $-1.08 * * *$ \\
\hline & $(-3.68)$ & $(-3.69)$ & $(-2.51)$ & $(-2.50)$ & $(-2.93)$ & $(-2.93)$ \\
\hline \# of observations & 15,533 & 15,533 & 15,533 & 15,533 & 15,533 & 15,533 \\
\hline R-squared & 0.0049 & 0.0049 & 0.0061 & 0.0062 & 0.0069 & 0.0069 \\
\hline Cluster & Firm, year & Firm, year & Firm, year & Firm, year & Firm, year & Firm, year \\
\hline Year FE & Yes & Yes & Yes & Yes & Yes & Yes \\
\hline Industry FE & Yes & Yes & Yes & Yes & Yes & Yes \\
\hline
\end{tabular}

Notes: This table presents coefficient estimates from the OLS regressions of intraday returns on country-, firm-, and conference-call-level characteristics. Low individualism is an indicator variable that equals one when the mean manager individualism is above the country median individualism and zero otherwise. The unit of analysis is an individual manager $(m)$ in an earnings conference call- quarter $(i, t)$. All variables are defined in Appendix B. Tstatistics are reported in parentheses below the regression coefficients. We cluster standards errors at the firm and year levels. ${ }^{* * *},{ }^{*}{ }^{* * *}$ denote significance at the $10 \%, 5 \%$, and $1 \%$ levels, respectively. ${ }^{\dagger}$ Denotes variables where we include an interaction term with the underlying variable and an indicator for missing observations in the regression model. 


\section{Table 9 Additional analyses}

Panel A: An alternative measure of individualism

\begin{tabular}{|c|c|c|c|}
\hline & (1) Tone_Q\&A $A_{i, m, t}$ & (2) Self-reference_Q\& $\mathrm{A}_{\mathrm{i}, \mathrm{m}, \mathrm{t}}$ & (3) Apologies_Q\& $\mathrm{A}_{\mathrm{i}, \mathrm{m}, \mathrm{t}}$ \\
\hline Predicted individualism $\mathrm{m}_{\mathrm{m}}$ & $\begin{array}{c}0.088 * * * \\
(4.275)\end{array}$ & $\begin{array}{c}0.163 * * * \\
(3.271)\end{array}$ & $\begin{array}{c}-0.012 * * * \\
(-4.636)\end{array}$ \\
\hline \# of observations & 129,787 & 129,787 & 129,787 \\
\hline R-squared & 0.0739 & 0.0736 & 0.0181 \\
\hline Cluster & Firm, year & Firm, year & Firm, year \\
\hline Controls in Table4 & Yes & Yes & Yes \\
\hline Year FE & Yes & Yes & Yes \\
\hline Industry FE & Yes & Yes & Yes \\
\hline
\end{tabular}

Panel B Including Firm Fixed Effects

\begin{tabular}{lccc}
\hline & $(1){\text { Tone_Q } \& \mathrm{~A}_{\mathrm{i}, \mathrm{m}, \mathrm{t}}}$ & (2) Self-reference_Q\& $\mathrm{A}_{\mathrm{i}, \mathrm{m}, \mathrm{t}}$ & (3) Apologies_Q\& $\mathrm{A}_{\mathrm{i}, \mathrm{m}, \mathrm{t}}$ \\
\hline Individualism $_{\mathrm{m}}$ & $0.049^{* * *}$ & $0.050^{* *}$ & $-0.005^{*}$ \\
& $(3.324)$ & $(2.535)$ & $(-1.701)$ \\
Observations & 129,787 & 129,787 & 129,787 \\
R-squared & 0.1745 & 0.2266 & 0.0943 \\
Cluster & Year & Year & Year \\
Controls in Panel A & Yes & Yes & Yes \\
Year FE & Yes & Yes & Yes \\
Firm FE & Yes & Yes & Yes \\
\hline
\end{tabular}

Panel C Change Specification

\begin{tabular}{|c|c|c|c|}
\hline & (1) Tone_Q\& $A_{i, m, t}$ & (2) Self-reference_Q\& $A_{i, m, t}$ & (3) Apologies_Q\&A $\mathrm{A}_{\mathrm{i}, \mathrm{m}, \mathrm{t}}$ \\
\hline Individualism $_{i}$ & $\begin{array}{l}0.0004 * \\
(1.7082)\end{array}$ & $\begin{array}{c}0.0000 \\
(1.0028)\end{array}$ & $\begin{array}{l}-0.0001 * * * \\
(-2.9008)\end{array}$ \\
\hline \# of observations & 54,087 & 54,087 & 54,087 \\
\hline R-squared & 0.0127 & 0.0300 & 0.0080 \\
\hline Cluster & Firm, year & Firm, year & Firm, year \\
\hline Controls in Table4 & Yes & Yes & Yes \\
\hline Year FE & Yes & Yes & Yes \\
\hline Industry FE & Yes & Yes & Yes \\
\hline
\end{tabular}

Panel D: Times of positive vs. negative earnings surprises

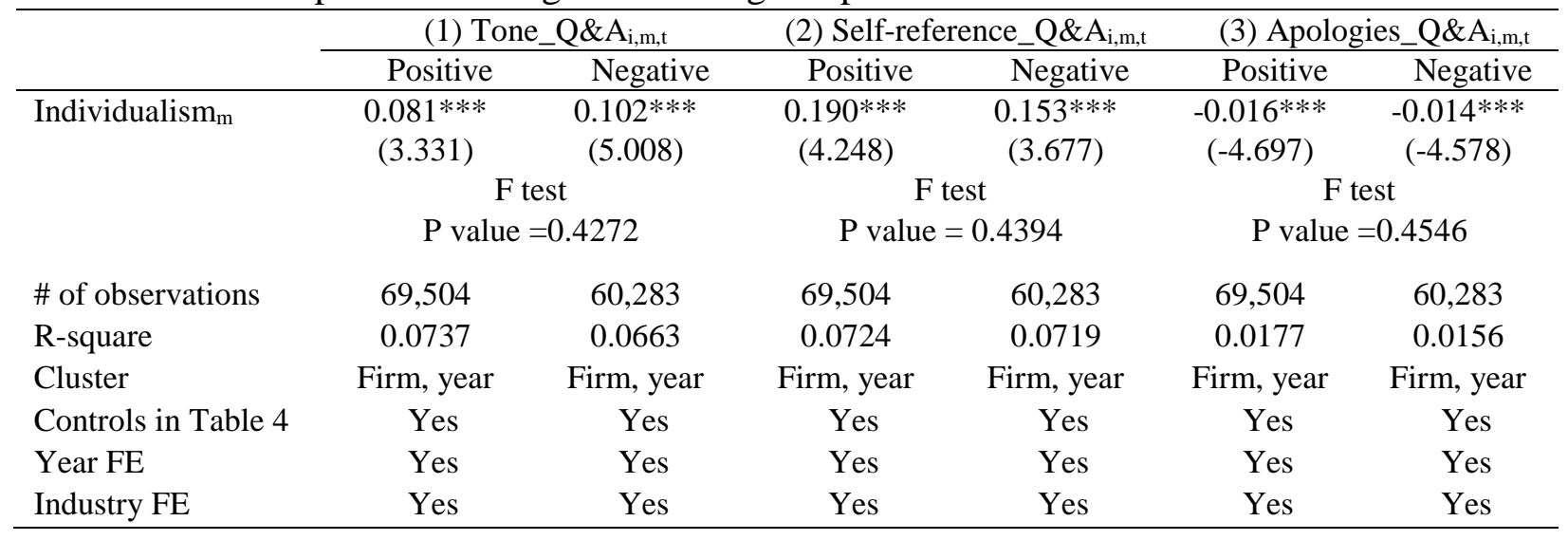


Notes: Panel A presents results for the second stage of the two stage least square regression where the Euclidean distance of the proportion of bloods types A and B by ethnicity is used as an additional explanatory variable of individualism in the first stage regression. Panel B presents coefficient estimates from the OLS regressions of disclosure attributes on various country-, firm-, and conference-call-level characteristics and includes firm fixed effects. Panel C presents coefficient estimates from the OLS regressions of disclosure attributes on various country-, firm-, and conference-call-level characteristics using a change specification for all variables. Panel D presents coefficient estimates from the OLS regressions of disclosure attributes, separately for observations with positive and negative earnings surprises. Earnings surprise is defined as the difference between the actual annual EPS minus the most recent mean analyst forecast, if available, or a seasonal random walk model otherwise. In Panels A, B, and D the unit of analysis is an individual manager $(m)$ in an earnings conference call- quarter $(i, t)$. In Panel $\mathrm{C}$, the unit of analysis is an earnings conference call- quarter $(i, t)$. All variables are defined in Appendix B. T-statistics are reported in parentheses below the regression coefficients. We cluster standards errors at the firm and year levels. *, **, and ${ }^{* * *}$ denote significance at the $10 \%, 5 \%$, and $1 \%$ levels, respectively. 


\section{Table 10 Sensitivity Analyses}

Panel A Measurement Error - Number of ethnicities by last name

\begin{tabular}{lccc}
\hline & $(1)$ Tone_Q\&A $_{\mathrm{i}, \mathrm{m}, \mathrm{t}}$ & $(2)$ Self-reference_Q\&A $\mathrm{i}, \mathrm{m}, \mathrm{t}$ & (3) Apologies_Q\&A $\mathrm{A}_{\mathrm{i}, \mathrm{m}, \mathrm{t}}$ \\
\hline Individualism $_{\mathrm{m}}$ & $0.101^{* * * *}$ & $0.209 * * *$ & $-0.017 * * *$ \\
& $(3.469)$ & $(3.138)$ & $(-3.925)$ \\
\# of Ethnicity & 0.010 & 0.019 & -0.001 \\
& $(0.487)$ & $(0.378)$ & $(-0.421)$ \\
\# of Ethnicity $\mathrm{x}$ & -0.009 & -0.032 & 0.002 \\
Individualism $_{\mathrm{m}}$ & $(-0.388)$ & $(-0.549)$ & $(0.643)$ \\
& & & \\
Observations & 129,787 & 129,787 & 129,787 \\
R-squared & 0.0694 & 0.0688 & 0.0163 \\
Cluster & Firm, year & Firm, year & Firm, year \\
Controls Table 4 & Yes & Yes & Yes \\
Year FE & Yes & Yes & Yes \\
Industry FE & Yes & Yes & Yes \\
\hline
\end{tabular}

Panel B Excluding female executives

\begin{tabular}{|c|c|c|c|}
\hline & (1) Tone_Q\&A $A_{i, m, t}$ & (2) Self-reference_Q\&A $A_{i m, t}$ & (3) Apologies_Q\& $A_{i, m, t}$ \\
\hline Individualism $_{\mathrm{m}}$ & $\begin{array}{c}0.099 * * * \\
(4.974)\end{array}$ & $\begin{array}{c}0.177 * * * \\
(4.315)\end{array}$ & $\begin{array}{c}-0.014 * * * \\
(-5.619)\end{array}$ \\
\hline Observations & 125,000 & 125,000 & 125,000 \\
\hline R-squared & 0.0670 & 0.0711 & 0.0161 \\
\hline Cluster & Firm, year & Firm, year & Firm, year \\
\hline Controls Table 4 & Yes & Yes & Yes \\
\hline Year FE & Yes & Yes & Yes \\
\hline Industry FE & Yes & Yes & Yes \\
\hline
\end{tabular}

Panel C Controlling for disclosure characteristics of the management discussions (MDs)

\begin{tabular}{|c|c|c|c|}
\hline & (1) Tone_Q\&A $A_{i, m, t}$ & (2) Self-reference_Q\& $\mathrm{A}_{\mathrm{i}, \mathrm{m}, \mathrm{t}}$ & (3) Apologies_Q\& $A_{i, m, t}$ \\
\hline Individualism $_{m}$ & $\begin{array}{c}0.113^{* * *} \\
(5.865)\end{array}$ & $\begin{array}{c}0.177 * * * \\
(3.885)\end{array}$ & $\begin{array}{c}-0.016^{* * * *} \\
(-6.174)\end{array}$ \\
\hline Tone_MD ${ }_{i, m, t}$ & $\begin{array}{l}0.280 * * * \\
(57.603)\end{array}$ & & \\
\hline Self-reference_MD ${ }_{i, m, t}$ & & $\begin{array}{c}0.206 * * * \\
(18.644)\end{array}$ & \\
\hline Apologies_MD ${ }_{\mathrm{i}, \mathrm{m}, \mathrm{t}}$ & & & $\begin{array}{c}0.215 * * * \\
(14.322)\end{array}$ \\
\hline Observations & 105,311 & 105,311 & 105,311 \\
\hline R-squared & 0.1268 & 0.0861 & 0.0215 \\
\hline Cluster & Firm, year & Firm, year & Firm, year \\
\hline Controls Table 4 & Yes & Yes & Yes \\
\hline Year FE & Yes & Yes & Yes \\
\hline Industry FE & Yes & Yes & Yes \\
\hline
\end{tabular}


Panel D: Using 3-day CAR

\begin{tabular}{|c|c|c|c|c|}
\hline & \multicolumn{2}{|c|}{ Cross-country sample } & \multicolumn{2}{|c|}{ U.S. only sample } \\
\hline & $(1)$ & $(2)$ & (3) & (4) \\
\hline Tone_Q\& $\mathrm{A}_{\mathrm{i}, \mathrm{t}}$ & $\begin{array}{l}2.35^{* * *} \\
(13.65)\end{array}$ & $\begin{array}{l}2.45 * * * \\
(10.42)\end{array}$ & $\begin{array}{c}2.80 * * * \\
(10.95)\end{array}$ & $\begin{array}{c}2.80 * * * \\
(10.16)\end{array}$ \\
\hline $\begin{array}{l}\text { Tone_Q\&A } \times \text { Low individualism } \\
\text { indicator }\end{array}$ & & $\begin{array}{c}-0.37 \\
(-1.23)\end{array}$ & & $\begin{array}{c}-0.02 \\
(-0.06)\end{array}$ \\
\hline Low individualism indicator & & $\begin{array}{c}0.10 \\
(0.77)\end{array}$ & & $\begin{array}{l}-0.08 \\
(-0.44)\end{array}$ \\
\hline $\begin{array}{l}\text { \# of observations } \\
\text { R-squared }\end{array}$ & $\begin{array}{l}55,399 \\
0.0521\end{array}$ & $\begin{array}{l}55,399 \\
0.0522\end{array}$ & $\begin{array}{l}39,145 \\
0.0699\end{array}$ & $\begin{array}{l}-10.17 \\
(-1.15)\end{array}$ \\
\hline Cluster & Firm, year & Firm, year & Firm, year & Firm, year \\
\hline Year FE & Yes & Yes & Yes & Yes \\
\hline Industry FE & $\begin{array}{l}\text { Yes } \\
\text { All } \\
\end{array}$ & $\begin{array}{l}\text { Yes } \\
\text { All }\end{array}$ & $\begin{array}{c}\text { Yes } \\
\text { US only }\end{array}$ & $\begin{array}{c}\text { Yes } \\
\text { US only }\end{array}$ \\
\hline
\end{tabular}

Notes: This table presents coefficient estimates from the OLS regressions of disclosure attributes on various country-, firm-, conference-call-level characteristics. Panel A presents results when controlling for the number of ethnicities by last name in our sample. Panel B present results excluding female executives. Panel C present results controlling for the MD section disclosure attributes. Panel D presents market reaction using 3-day CAR. In panels A, B, and C the unit of analysis is an individual manager $(m)$ in an earnings conference call- quarter $(i, t)$. In Panel $\mathrm{D}$, the unit of analysis is an earnings conference call- quarter $(i, t)$. All variables are defined in Appendix B. T-statistics are reported in parentheses below the regression coefficients. We cluster standards errors at the firm and year levels. *, ${ }^{* *}$, and ${ }^{* * *}$ denote significance at the $10 \%, 5 \%$, and $1 \%$ levels, respectively. 